\title{
Visibility of Synaptically Induced Conductance Changes: Theory and Simulations of Anatomically Characterized Cortical Pyramidal Cells
}

\author{
Christof Koch, ${ }^{1}$ Rodney Douglas, ${ }^{2}$ and Udo Wehmeier \\ 'Computation and Neural Systems Program, 216-76, California Institute of Technology, Pasadena, California 91125, and \\ ${ }^{2}$ MRC Anatomical Neuropharmacology Unit, Department of Pharmacology, Oxford OX1 3QT, United Kingdom
}

A recent report has provided evidence that there are no significant increases in the neuronal input conductance during the response of cortical cells in cat visual cortex to nonpreferred visual stimuli (Douglas et al., 1988). A criticism of experiments of this kind is that changes in the membrane conductance occurring in the dendritic tree may not be visible from electrodes that impale the soma. Our paper describes theoretical and numerical results concerning the visibility of synaptically induced conductance changes from intracellular electrodes, in both ideal and anatomically wellcharacterized cortical neurons.

Based on earlier work by Rall (1967), we here derive theoretical expressions for the change in input conductance at any location in a passive dendritic tree resulting from activation of a single synapse and obtain bounds for the effects of multiple synapses. We find that the conductance change measured at the cell body is always less than the sum of the synaptic conductance changes and that this observed conductance change does not depend on the synaptic reversal potential. For the case of an infinite dendritic cylinder, the change in input resistance due to a single synaptic input decays exponentially with distance of the synapse from the recording site. Numerical simulations of synaptic inputs that change approximately as fast as the membrane time-constant produce an increase in input conductance that is only slightly less visible than that of a constant input. We also compute the changes in somatic input conductance of 2 morphologically identified pyramidal cells from cat visual cortex during activity of a single inhibitory basket cell with known synaptic input locations. We find that the increase in conductance due to the activity of the inhibitory basket cells is clearly visible from the cell body of the pyramidal cells and that a $70 \%$ reduction in the amplitude of excitation is associated with at least a $30 \%$ increase in somatic input conductance, which would be visible in intracellular recordings.

\footnotetext{
Received July 10, 1989; revised Oct. 16, 1989; accepted Nov. 28, 1989.

We thank Joln Anderson for his devotion to histology, and Ferenc Mechler for writing some of the programs. We also thank Kevan Martin and David Ferster for detailed comments. Our collaboration was made possible by a Bioscience Grant for International Joint Research from the New Energy and Industrial Technology Development Organization in Japan. C.K. is supported by grants from the Air Force Office of Scientific Research, the James S. McDonnell Foundation, and a Presidential Young Investigator Award from the National Science Foundation. R.J.D. acknowledges the support of the Medical Research Council of the United Kingdom, the Medical Research Council of South Africa, and the University of Cape Town.

Correspondence should be addressed to Christof Koch at the above address. Copyright (C) 1990 Society for Neuroscience $0270-6474 / 90 / 061728-17 \$ 02.00 / 0$
}

Taken together with the negative experimental evidence of Douglas et al. (1988), our results cast doubt on a large class of models of direction selectivity that rely on synaptically mediated inhibitory conductance increases to veto or block excitatory conductances increases.

Most theories of neuronal information processing assume that temporal patterns of action potentials constitute the major output variable of nerve cells. The generation of action potentials at the initial segment depends on the interplay of excitatory and inhibitory synaptic inputs applied to the dendritic tree and cell body (Rall, 1964, 1989; Shepherd, 1972; Torre and Poggio, 1981; Koch et al., 1982; Segev and Parnas, 1983). But what is the strategy of synaptic inhibition in the control of neuronal discharge? Is its role just broadly permissive, for instance to contain cortical excitability, or does inhibition act specifically and very selectively to block other synaptic inputs to parts of the dendritic tree (Rall, 1964; Blomfield, 1974; Torre and Poggio, 1978; Koch and Poggio, 1987)? This question has been raised in particular for inhibition whose reversal potential is close or equal to the resting potential of the cell, i.e., silent or shunting inhibition.

Shunting inhibition is both nonlinear and local in its effect (Blomfield, 1974; Torre and Poggio, 1978; Koch et al., 1982, 1983), and these are crucial properties in a number of models that explain the selective nature of neuronal responses. For instance, Barlow and Levick (1965) proposed that directional selectivity of retinal ganglion cells is best explained by a veto-like operation; i.e., inhibition prevents the cell from responding in the null direction by blocking synaptic evoked excitation. Torre and Poggio (1978) and Koch et al. $(1982,1983)$ proposed a detailed biophysical implementation of Barlow and Levick's AND-NOT scheme, where shunting or silent inhibition blocks the cell's response in the null direction. Using linear cable theory to simulate retinal ganglion cells, they showed that the nonlinear interaction between synaptic induced conductance changes has the required nonlinearity and locality to subserve directional selectivity: an inhibitory synapse of the shunting types located either in the neighborhood of an excitatory synapse or on the direct path between excitation and the soma can strongly reduce the excitatory postsynaptic potential (EPSP) in the soma, provided that the size of the inhibitory conductance change is at least as large as the synaptic input conductance (Koch et al., 1982; see also Rall, 1964). Intracellular recordings in turtle directional selective ganglion cells (Marchiafava, 1979) revealed an inhibitory conductance increase with a reversal potential close to the resting potential of the cell, suggesting silent or 
shunting inhibition. Evidence of nonlinear interactions in these cells has been obtained from extracellular recordings (Grzywacz and Amthor, 1989).

Shunting inhibition was incorporated into models explaining the selective responses of cells in the visual cortex to various stimuli (orientation and directional selectivity: Sillito, 1975; Sillito et al., 1980; Heggelund, 198 1 a, b; Koch and Poggio, 1986; binocular disparity: Ferster, 1981; Koch and Poggio, 1987). Extracellular techniques suggested a nonlinear interaction between inhibition and excitation (Rose, 1977; Dean et al., 1980). A number of intracellular studies have reported small inhibitory postsynaptic potentials (IPSPs) in response to visual stimulation (Creutzfeldt et al., 1974; and, in particular, Ferster, 1986, 1987), but did not measure changes in input conductance. However, Douglas et al. (1988) have made direct measurements of the input conductance of neurons in cat visual cortex during visual stimulation. They found that there was no significant increase in neuronal input conductance during periods when large inhibitory synaptic conductance increases might be expected to be active, i.e., during motion of a bar in the cell's null direction or for a bar oriented orthogonal to the cell's optimal orientation. Nevertheless, with their techniques they were able to measure large conductance increases during electrically evoked IPSPs in in vitro slices of rat and cat visual cortex (Berman et al., 1989). Thus, their results are inconsistent with theories that depend on massive inhibitory synaptic input to explain the selective responses of cortical neurons to visual stimuli.

There are 2 difficulties with intracellular experiments of this kind. First, the evaluation of changes in membrane conductance due to synaptic input are indirect. Conductance changes are inferred from recordings of the change in intracellular potential evoked by a small current step. This measurement must be performed both in the quiescent state and during activation of the synaptic input. Second, the intracellular electrode is usually located at the cell body or in the relatively thick proximal dendrites, while the synaptic conductance changes can be located on dendritic spines or distal dendrites that are inaccessible to the recording electrode. How reliably, then, can one conclude that the absence of measurable changes in the input conductance implies absence of any large synaptic induced conductance changes? In this study, we derive upper bounds on the "visibility" of conductance changes from the soma and compute examples of interaction between excitatory and inhibitory synapses using anatomical data obtained from neurons in cat visual cortex.

One of the first explicit attempts to study the transient changes in input conductance seen by a recording electrode at the soma was made in a series of papers in 1967 (Smith et al., 1967; Rall, 1967; Rall et al., 1967). Using intracellular recordings in cat spinal motoneurons, Smith and colleagues showed that IPSPs were invariably accompanied by decreases in the somatic input impedance, while less than half the EPSPs studied were associated with detectable input impedance changes (see also Jack et al., 1971). Rall (1967) used numerical simulations of the underlying cable equation to estimate the detectability of transient synaptic conductance inputs from somatic recordings. Rall et al. attempted to correlate the detectability of impedance changes with synaptic location, concluding from the above data that inhibitory synapses are located at or close to the soma, while most of the excitatory synapses are located in the dendritic tree. The insights derived from this work were extended by a number of authors (e.g., Jack et al., 1975; Carlen and Durand,
1981; Carnevale and Johnston, 1982; Durand, 1984; Fox and Chan, 1985). Based on these studies by Rall and his colleagues, we here lay out the framework for deriving exact upper bounds on the "visibility" of changes in the input conductance and their dependence on various geometrical and biophysical parameters in passive dendritic trees.

\section{Analytical Results}

Let us first derive the voltage change in a dendritic tree with arbitrary gcomctry (as long as no loops are present) in response to synaptic input. We will assume that the membrane contains no active, voltage-dependent components. This approximation is reasonable if postsynaptic potentials, as well as the voltage induced by current injection via the intracellular electrode, remain within the linear regime of the neuronal membrane.

\section{Somatic conductance change in response to a single} synaptic input

In a passive dendritic tree (Fig. $1 \mathrm{~A}$ ), the current at location $i$, $I_{i}$, due to a synaptic-induced conductance change at location $i$, $g_{i}(t)$, with the synaptic reversal potential $E$, is given by

$$
I_{i}(t)=g_{i}(t)\left[E-V_{i}(t)\right]
$$

where $V_{i}(t)$ is the postsynaptic membrane depolarization at location $i$. The voltages $E$ and $V_{i}$ are always expressed relative to the cell's resting potential $E_{\text {rest }}$. It follows from Ohm's law that the postsynaptic potential is

$$
V_{i}(t)=K_{i u}(t) * I_{i}(t)=K_{i i}(t) *\left\{g_{i}(t)\left[E-V_{i}^{\prime}(t)\right]\right\}
$$

where $K_{u}(t)$ is the time-dependent input impedance at location $i$ and * represents convolution. This relationship can be simplified by assuming that the synaptic conductance change $g_{i}(t)$ is much slower than the membrane time constant $\tau_{m}$, so that only the stationary behavior of Eq. (2) need be considered. In this case the convolution can be replaced by a multiplication, and the function $K_{i i}(t)$ by its steady-state value, denoted here by $K_{i i}$ and corresponding to the steady-state input resistance at location $i$. Thus, we now have

$$
V_{i}=K_{u} g_{i}\left(E-V_{i}\right)
$$

or

$$
V_{i}=\frac{g_{i} K_{i i} E}{1+g_{i} K_{i i}}
$$

If $E>E_{\text {rest }}$, then an increase in conductance results in a positive (depolarizing) PSP. If $E<E_{\text {rest }}$, then the PSP is negative (hyperpolarizing). Finally, if $E=E_{\text {ress }}$, then $V_{i}=0$. That is, no voltage change is observed despite the increase in synaptic conductance. Such a synapse has been referred to as "shunting" inhibition (Torre and Poggio, 1978). However, electrophysiologists often refer to shunting inhibition in the context of a large conductance "shunting" excitatory current and have less regard for whether the synaptic battery reverses at rest or below the resting potential. In order to avoid any further confusion, we refer to inhibition with a reversal potential at the resting potential as "silent" inhibition.

Let us now assume that the PSP evoked at $i$ is being recorded from some location other than $i$, for instance at the cell body $s$ (Fig. $1 A$ ). Then, the potential induced at the soma, $V_{s}$, is obtained from Ohm's law, 
Figure 1. A, The question we are investigating is to what extent a synaptic induced conductance change $g_{i}$ at location $i$ somewhere in an arbitrary branched dendritic tree can be detected by an intracellular electrode at the soma $s$. We assume in this study that neither the synaptic input nor the electrode depolarizes the cell sufficiently to evoke nonlinear membrane responses. $B$, Our idealized neuron consisted of 400 passive compartments that represented the soma, two 1.2-mm-long main dendrites (of constant $1.5 \mu \mathrm{m}$ diameter) with secondary $0.5-\mu \mathrm{m}$-thick and $10-\mu \mathrm{m}$-long dendritic branches.

$$
V_{s}=K_{i s} I_{i}=K_{i s} \frac{V_{i}}{K_{i i}}=\frac{g_{i} K_{i s} E}{1+g_{i} K_{i i}}
$$

Here, $K_{t s}$ is the transfer resistance that is measured by injecting current at location $i$ and recording the resulting voltage change at location $s$. Transfer resistances have a number of interesting properties (Koch et al., 1982), two of which are relevant to the present problem. The first of these is symmetry: $K_{i j}=K_{j i}$. This means that the voltage change observed at location $j$ when the current $I$ is injected at location $i$ is identical to the voltage change obscrved at location $i$ when the same current $I$ is injected at location $j$. Second, the input resistances at 2 separate locations $i$ and $j, K_{i i}$ and $K_{j j}$, are always larger than the transfer resistance $K_{i j \cdot}{ }^{3}$

The current observed at the soma in response to the synaptic event is

$$
I_{s}=\frac{V_{s}}{K_{s s}}=\frac{1}{K_{s s}} \frac{y_{i} K_{i s} E}{1+g_{i} K_{i i}}
$$

where $K_{s s}$ is the somatic input resistance. Experimentally, the somatic input resistance is obtained by measuring the change in membrane potential induced by the injection of a small steadystate current $I_{s}$ via the electrode. This current is small, so that the cell remains in its linear range. The quiescent input resistance, i.e., the input resistance in the absence of any synaptic input, is

$$
K_{s s}=\frac{V_{s}}{I_{s}}
$$

However, when the input resistance is measured in the presence of synaptic input, the following 2 linearly coupled equations must be solved (Koch et al., 1982):

$$
\begin{aligned}
& V_{i}=g_{i} K_{i i}\left(E-V_{i}\right)+K_{i s} I_{s} \\
& V_{s}^{\prime}=g_{i} K_{i s}\left(E-V_{i}\right)+K_{s s} I_{s}
\end{aligned}
$$

Simple algebraic manipulations of these equations result in

$$
V_{s}^{\prime}=\frac{g_{i} K_{i s} E}{1+g_{i} K_{i i}}+\left(K_{s s}-\frac{g_{i} K_{i s}^{2}}{1+g_{i} K_{i i}}\right) I_{s}
$$

\footnotetext{
${ }^{3}$ Note that our definition of the transfer resistance between location 1 and the soma $s, K_{1 s}$, is related to, but different from, the electrotonic coupling coefficients, $\kappa_{12}$ and $\kappa_{21}$ of Carnevale and Johnston (1982). Their exact relationship is given by $\kappa_{12}=K_{1 s} / K_{s s}$ and $\kappa_{21}=K_{1 s} / K_{11}$.
}

The first term is identical to the value of the postsynaptic potential induced by $g_{i}$ in the absence of current injection [Eq. (5)]. The second term is proportional to the injected current. As in standard electrophysiological practice, the PSP (first term) is subtracted to obtain

$$
V_{s}^{\prime \prime}-V_{s}=K_{s s}^{*} I_{s}
$$

where $K_{s s}^{*}$ is the new somatic input resistance defined as

$$
K_{s s}^{*}=K_{s s}-\frac{g_{i} K_{i s}^{2}}{1+g_{i} K_{i i}}
$$

The change in input resistance,

$$
\Delta K_{s s}=K_{s s}^{*}-K_{s s}=\frac{-g_{i} K_{i s}^{2}}{1+g_{i} K_{i i}}
$$

in response to a synaptic input is thus always negative for an incrcasc in membranc conductance $\left(g_{i}>0\right)$. That is, the new input resistance is lower than the original value. Equation (12) is easily understood. The current $I_{s}$ injected into the soma induces a voltage $K_{i s} I_{s}$ at the location of the synapse $i$. This voltage provides a synaptic driving force that converts the synaptic input, $g_{i}$, into a voltage at location $i, g_{i} K_{i i} K_{i s} I_{s} /\left(1+g_{i} K_{i i}\right)$, or into a voltage change at the soma, $g_{i} K_{i s} I_{s} /\left(1+g_{i} K_{i i}\right)$. Thus, the higher the inpul resistance at the location of the synapse $\left(K_{i i}\right)$, the lower the visible change of input resistance at the soma. Similarly, the further the synapse $i$ is removed from the soma, the smaller $\Delta K_{s s}$ (because $K_{i s} \rightarrow 0$ ). Furthermore, for a given synaptic site, $\Delta K_{s s}$ does not depend linearly on the synaptic conductance change. It reaches a limiting value $-K_{i s}^{2} / K_{i i}$ as $g_{i} \rightarrow \infty$. Thus, even large synaptic inputs may not be readily visible if they are located on a thin distal dendrite, or on a spine. Note that the new value of the input resistance does not depend on the synaptic reversal potential. Consequently, hyperpolarizing, silent, or depolarizing synaptic conductance changes are all equally visible (or invisible) from the recording electrode. The appropriate equations for the somatic input conductance are

$$
G_{s s}^{*}=\frac{1}{K_{s s}^{*}}=\frac{1+g_{i} K_{i i}}{K_{s s}+g_{i}\left(K_{s s} K_{i i}-K_{i s}^{2}\right)}
$$

and

$$
\Delta G_{s s}=G_{s s}^{*}-G_{s s}=\frac{g_{i} K_{l s}^{2}}{K_{s s}^{2}+g_{i} K_{s s}\left(K_{s s} K_{i i}-K_{i s}^{2}\right)}
$$


with $\Delta G_{s s}>0$ for $g_{i}>0$ and where $G_{s s}$ and $G_{s s}^{*}$ denute the values of the somatic input conductance in the absence and in the presence of synaptic input.

\section{Synaptic visibility}

In order to characterize in a single number the fraction of the synaptic conductance change $g_{i}$ which can in principle be detected via an intracellular electrode at the soma, we introduce the visibility factor $\Gamma$ as

$$
\Gamma=\frac{\Delta G_{s s}}{g_{i}}=\frac{K_{i s}^{2}}{K_{s s}^{2}+g_{i} K_{s s}\left(K_{i i} K_{s s}-K_{i s}^{2}\right)}
$$

Keeping in mind the properties of the transfer resistances, in particular, $\left(K_{i i} K_{j j}-K_{i j}^{2}\right) \geq 0$ (Koch et al., 1982), it is relatively straightforward to show that for $g_{i}>0$,

$$
0 \leq \Gamma \leq 1
$$

That is, the maximum increase in somatic input conductance is bounded by the synaptic conductance change. If the synaptic input is located at the soma, we have $\Gamma=1$; the further the synaptic input is removed from the soma, the smaller the observed change in somatic conductance and $\Gamma \rightarrow 0$. Note that $\Gamma$ represents an upper bound on the synaptic visibility, because noise considerations and the quality of the intracellular impalement (see below) will further limit the "detectability" of any synaptic input.

The visibility of synaptic input as a function of distance between synapse and electrode can be assessed for the case of an infinite passive dendrite of constant diameter $d$ (see also Rall, 1967). In this case, the transfer resistance is simply $K_{i j}=K_{i i} e^{-X}$ (Jack et al., 1975), where $X$ is the electrotonic distance between the current injecting electrode and the synapse, $X=x / \lambda$, with the length constant $\lambda=\left(d R_{m} / 4 R_{i}\right)^{1 / 2}$ and the input resistance $K_{i i}=\left[R_{i} R_{m} /\left(\pi^{2} d^{3}\right)\right]^{1 / 2}$ with $R_{i}$ the intracellular resistivity (in $\Omega \mathrm{cm}$ ) and $R_{m}$ the membrane resistance (in $\Omega \mathrm{cm}^{2}$ ). Thus, the change in somatic input resistance is

$$
\Delta K_{s s}=\frac{-g_{i} K_{i i}^{2} e^{-2 X}}{1+g_{i} K_{i i}}
$$

and the visibility

$$
\Gamma=\frac{e^{-2 X}}{1+g_{i} K_{i i}\left(1-e^{-2 x}\right)}
$$

This result shows that the change in somatic input resistance decays exponentially with a space constant of $\lambda / 2$ and that the decay is not dependent on reversal potential. The factor $1 / 2$ arises from the fact that the current injected at $s$ must propagate to the site of the synapse $i$ and then propagate back to the voltagerecording electrode at $s$ (see Fig. 2). For a typical dendrite (see below) with $R_{i}=100 \Omega, R_{m}=10,000 \Omega \mathrm{cm}^{2}$ and $d=1.5 \mu \mathrm{m}$, we have $K_{i i}=173 \mathrm{M} \Omega$ and $\lambda=612 \mu \mathrm{m}$. We plot in Figure 2 the visibility $\Gamma$ associated with a small synaptic input $\left(g_{i}=1\right.$ $n S)$ for such an infinite cable. Note that in this case $\Gamma$ is approximately proportional to $e^{-2 x}$.

\section{Effect of somatic leak}

How are these results affected by possible damage to the somatic membrane due to impalement by the electrode? We can model
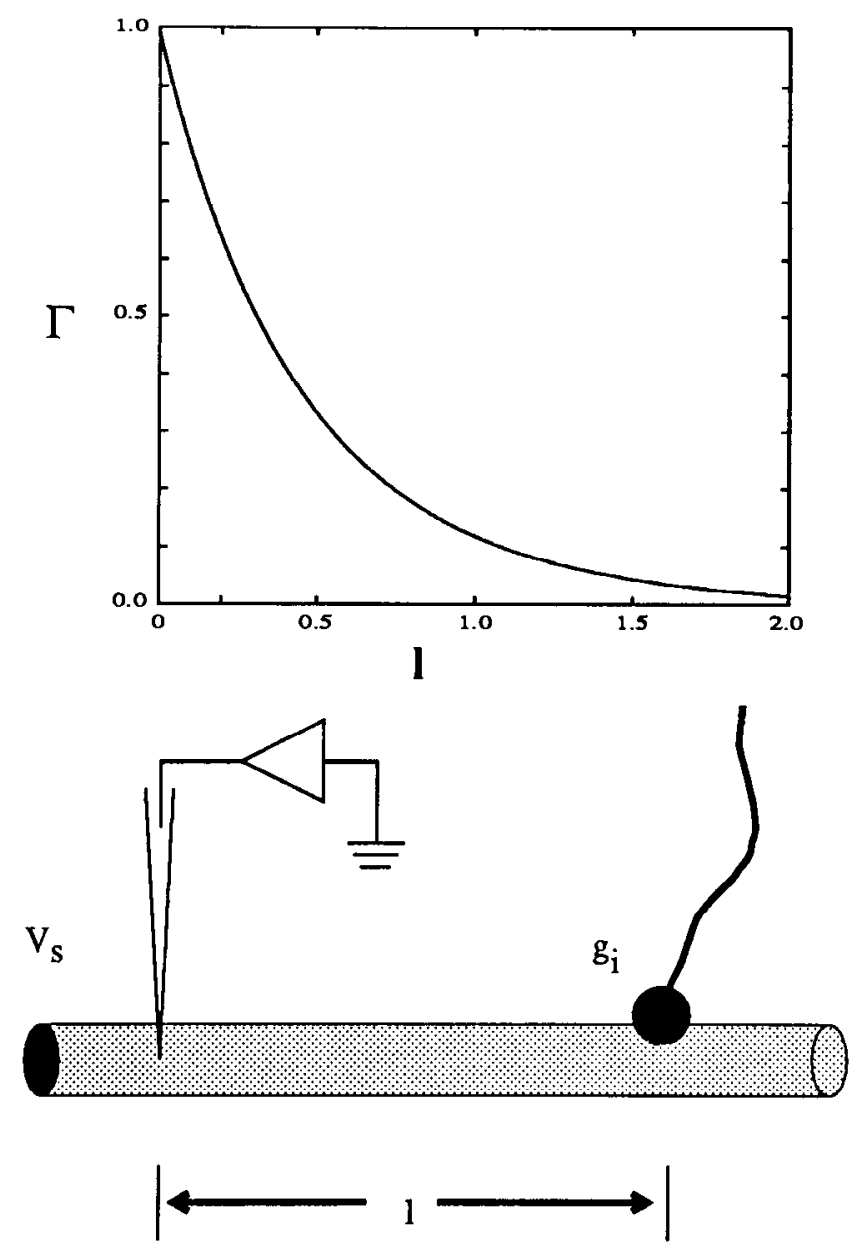

Figure 2. The visibility $\Gamma$, defined in Eq. (15) as the ratio of the change in somatic input conductance $\Delta G$ to the synaptic input $g_{\text {i }}$ (here $g_{l}=1$ $\mathrm{nS})$ in an infinite dendrite of constant diameter $(d=1.5 \mu \mathrm{m})$ as a function of the electrotonic distance $x / \lambda$.

this situation by adding a conductance $G_{\text {leak }}$ to the cell body so that the new somatic input conductance is given by $G_{s s}^{\text {new }}=G_{s s}$ $+G_{\text {leak }}$. The leak conductance has a reversal potential $E_{0}$ positive to the resting potential, i.e., $E_{0}>0$. We modify Eq. (8) as follows:

$$
\begin{aligned}
V_{i} & =g_{i} K_{i i}\left(E-V_{i}\right)+K_{i s} I_{s}+G_{\text {leak }} K_{i s}\left(E_{0}-V_{s}^{\prime}\right) \\
V_{s}^{\prime} & =g_{i} K_{i s}\left(E-V_{i}\right)+K_{s s} I_{s}+G_{\text {leak }} K_{s s}\left(E_{0}-V_{s}^{\prime}\right)
\end{aligned}
$$

Appropriate algebraic manipulations lead to the result that the new value of the somatic conductance (slope conductance) during the synaptic input is just

$$
G_{s s}^{\mathrm{new}}=\frac{1+g_{i} K_{i i}}{K_{s s}+g_{i}\left(K_{s s} K_{i i}-K_{i s}^{2}\right)}+G_{\mathrm{lcak}}
$$

that is, the sum of the input conductance in the absence of the leak plus $G_{\text {leak }}$. Moreover, an offset current, proportional to $G_{\text {lcak }} E_{0}$ will flow. Thus, the absolute change in somatic input conductance, $\Delta G_{s s}$, is independent of the leak caused by the electrode. Of course, the change in somatic input conductance relative to the somatic input conductance (i.e., $\Delta G / G_{s s}^{*}$ ) will decrease in the presence of the leak. 


\section{Somatic conductance change in response to multiple synaptic inputs}

So far we have only considered the case of a single synaptic input. In practice, however, a large number of synaptic inputs are likely to be activated during a response to physiological input, and so the neuron is subjected to a complex barrage of excitation and inhibition. The synaptic conductance inputs interact nonlinearly (Rall, 1964; Torre and Poggio, 1981), and the resulting membrane potential is not the linear sum of the individual synaptic contributions to the somatic potential, but is smaller. Nonlinear interaction will affect the measured changes in somatic input resistance in a similar way. It is laborious but quite straightforward to show that the change in somatic input resistance $\Delta K_{n}^{\prime \prime}=K_{,+}^{+*}-K_{,+}^{+j}$ in response to 2 synaptic inputs $g_{\text {, and }} g_{\text {, (at }} 2$ distinct locations, $i$ and $j$, and with 2 distinct synaptic reversal potentials, $E_{i}$ and $E_{j}$ ) is given by

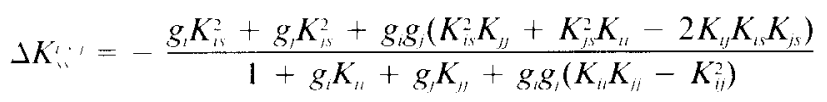

Similar to Eq. (12), the change in input resistance is independent of the reversal potential of either synapse. Furthermore, $\Delta K_{* r}^{i+j}$ obeys the following inequality,

$$
\Delta K_{,,}+\Delta K_{s,}<\Delta K_{,+,}^{\prime+1}
$$

or, because all these quantities are negative (for $g_{i} \geq 0$ and $g_{\text {. }}$ >)

$$
\left|\Delta K_{n}^{r_{n}}\right|+\left|\Delta K_{n}^{i}\right| \geq\left|\Delta K_{w}^{i+i}\right|
$$

Thus, the change in somatic input resistance due to the simultaneous activation of both synapses $i$ and $j$ is always less than or equal to the change in somatic input resistance due to the synaptic input at $i, \Delta K_{s,}$, plus the change in input resistance due

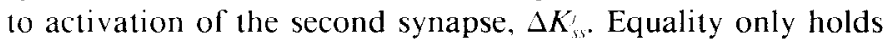
if the 2 synapses are completely decoupled, i.e., $K_{i j}=0$. In other words, the change in somatic input resistance when activating numerous synaptic inputs is always less than the sum of the changes in input resistance when the synaptic inputs occur by themselves. The amount of sublinear behavior depends on the product of the input resistance at the synapse, $K_{i i}$, and the conductance input $g_{\text {. }}$. Numerically (see below), we observe a similar sublinear behavior for the synaptic visibilities $(\Gamma)$, that is, the visibilities of 2 simultaneous active synapses are less than the visibility of the sum of the 2 by themselves, although we have no rigorous proof for this result.

Our analytical results only apply to stationary synaptic input. We did not attempt to prove any analogous results for timedependent conductance changes. Transient changes in the membrane conductance of a passive cell will be less visible from the soma than their stationary counterparts, because the charging of the membrane capacitance delays the rise of the membrane potential to its final level. This result was first stated and discussed by Rall (1967) and is confirmed by our computer simulations (see below).

The input conductance of a neuron is measured by recording the change in voltage induced by a rectangular current injection. The duration of the current injection is usually much longer than the membrane time constant, so that the measurement of voltage deflection can be made after the membrane has settled to its new level. An alternative method, using short current pulses, was suggested by Barrett and Barrett (1976) and used by
Carlen and Durand (1981) in their analog cable model. If a rectangular current pulse of amplitude $I_{0}$ is applied from $t=0$ until $t=T$, then the input conductance can be approximated by the following expression:

$$
G_{i, i} \approx \frac{I_{t i} T}{\int_{0}^{x} V(t) d t}
$$

For a passive system such as ours, $G_{t h}$ is always larger than the true input conductance $G_{s s}$; in other words, this method consistently overestimates the input conductance, thereby underestimating the input resistance $R_{m}$. If $T$ is long enough to allow the membrane potential to converge to its final value in response to the current step, $G_{i n}$ converges to its true value $G_{,}$(see Fig. 7). To measure the change in input resistance, the voltage response $V(t)$ must be integrated as indicated in Eq. (24) during the synaptic input and subtracted from the measured $i_{i, j}$ in the absence of any input. Thus, besides overestimating the truc input conductance, this method suffers from the same principal limitations as does the method we discuss. Because this shortpulse method is thus less accurate than our more exact method. we refrain from using it.

\section{Numerical Simulations}

In the previous section, we derived an exact upper bound on the visibility of synaptic conductance changes as secn by an intracellular electrode at the soma of a passive, but otherwise arbitrary complex dendritic tree. However, to provide a satisfactory answer to our initial question - "Can inhibition act selectively to block excitatory input in cat cortical cells without being visible from the soma?" - we will now flesh out this analytical framework with the help of 2 sets of simulations. In the first, we solve numerically the time-dependent cable equation for an idealized passive neuron whose properties bear some relationship to those of a retinal neuron. In the second, we compute the changes in somatic input conductance resulting from stationary synaptic input for 2 anatomically characterized cortical pyramidal cells with known distributions of inhibitory input.

\section{Methods and parameters \\ Idealized neuron}

We assume a neuron that consists of a $15-\mu \mathrm{m}$-diameter spherical soma and two 1.5- $\mu \mathrm{m}$-diameter cylindrical main dendrites. These dendrites give rise to multiple secondary stub branches (Fig. 1). The soma is represented by a lumped resistance and capacitance and the dendrites by a number of passive $\mathrm{RC}$ membrane compartments (Fig. $1 B$ ). The membrane parameters are assigned standard values: $C_{m}-1 \mu \mathrm{F} \mathrm{cm}{ }^{2} ; R_{m}=10,000 \Omega \mathrm{cm}^{2} ; R_{i}=100$ $\Omega \mathrm{cm}$, leading to a membrane time constant of $\tau_{m}=10 \mathrm{msec}$ and a dendritic space constant of about $\lambda=600 \mu \mathrm{m}$.

Each dendritic compartment is $25 \mu \mathrm{m}$ long, equivalent to $4 \%$ of $\lambda$. The total length of each dendrite was $1.2 \mathrm{~mm}$. The main dendrites give rise to secondary stubs at intervals of $25 \mu \mathrm{m}$. These stubs represent high-impedance synaptic input sites such as small secondary dendrites, or spines. Each stub is $10 \mu \mathrm{m}$ long and $0.5 \mu \mathrm{m}$ in diameter and is represented by a single compartment. The model neuron altogether consists of about 400 RC compartments. We assume sealed-end boundary conditions. The appropriate cable equation is solved by the Crank-Nicolson 

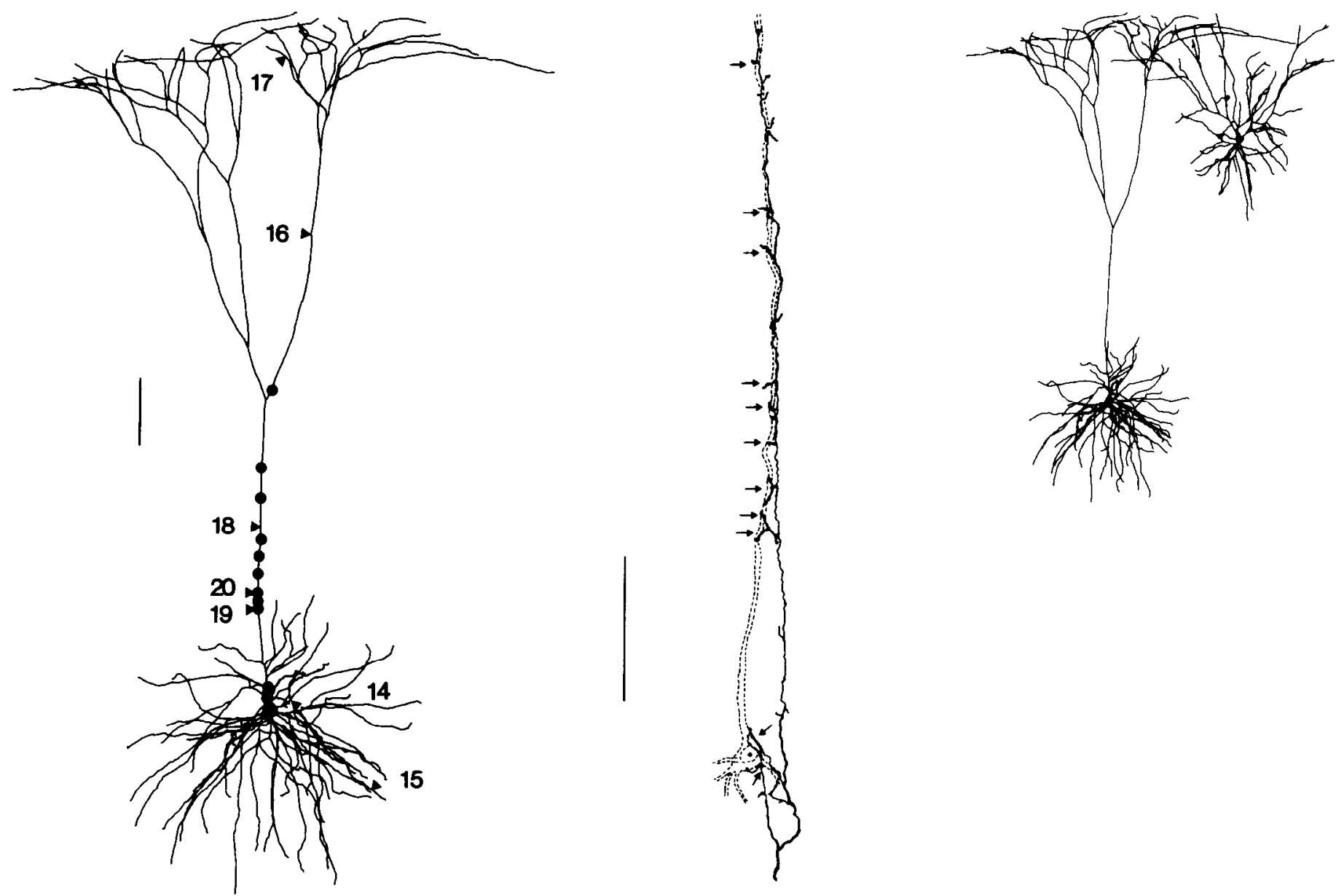

Figure 3. A, Computer plot of a reconstructed layer 5 pyramidal cell. The filled circles indicate the locations of 16 basket cell synapses obtained from the reconstruction shown in $B$. Four of the 16 synapses are located on the soma. Numbered arrowheads indicate the locations of spines that received excitatory inputs. The inhibitory synapses adjacent to spines 19 and 20 are usually applied to the trunk dendrite, but share the spines with the excitatory synapses in some computations. The apical dendrite is quite thick, tapering from $8 \mu \mathrm{m}$ just beyond the soma to $4.4 \mu \mathrm{m}$ at synapse 18 to $1.7 \mu \mathrm{m}$ at synapse 16 . Scale bar, $100 \mu \mathrm{m}$. Inset compares the size of this pyramidal cell with the superficial pyramidal cell shown in Figure $4 A$. B. Afferent of layer $5 / 6$ basket cell making synaptic contact with a layer 5 pyramidal cell. Redrawn from figure 3 of Kisvarday et al. (1986), with permission. The arrows point to the synaptic contacts that were transposed to the cell shown in $A$. Scale bar, $100 \mu \mathrm{m}$.

(1947) technique, which is second-order in both space and time, and is absolutely stable (for more details, see Mascagni, 1989). The somatic input resistance of the model neuron is $149 \mathrm{M} \Omega$, corresponding to $G_{s}=6.71 \mathrm{nS}$.

An $\alpha$ function is used to model synaptic input (Jack et al., 1975), because this function appears to describe synaptic induced changes in membrane conductance quite well for vertebrate sympathetic ganglion cells (Yamada et al., 1989):

$$
g(t)=\text { const } \cdot t e^{-t / t_{\text {peak }}}
$$

$g_{\text {peak }}$ being the maximum increase in membrane conductance at time $t_{\text {peak }} ;$ that is $g_{\text {peak }}=g\left(t_{\text {peak }}\right)$. The function $g(t)$ decays to $1 \%$ of $g_{\text {peak }}$ at about $t=7.64 t_{\text {peak }}$.

$G_{\mathrm{ss}}^{*}$ is computed in the following fashion for transient inputs. A current pulse of long duration is injected at the soma. When the membrane voltage settles to its stationary value, the synaptic input is activated. The voltage response to synaptic activation alone is then subtracted from the response to combined current injection and synaptic activation. The maximal ratio of injected current to voltage difference between the 2 responses is then defined to be the somatic input conductance $G_{s .}^{*}$. This procedure corresponds closely to our definition of input conductance for stationary synaptic input [Eqs. (8-11)].

\section{Cortical pyramidal cells}

The 3-dimensional structures of 2 pyramidal neurons and the detailed synaptic terminations of 2 basket cells are used to investigate the visibility problem for the specific case of cat striate cortex. These were selected because pyramidal cells are the major excitatory cell type in the cortex and the basket cells appear to be the most common putative inhibitory cell providing input to cortical pyramidal cells (Martin, 1988). We investigate 2 cases: the effect of a layer $5 / 6$ basket cell inhibiting a layer 5 pyramidal cell, and the effect of a layer $3 / 4$ basket cell on a layer $2 / 3$ pyramidal cell.

The basket cells and pyramidal neurons (Figs. 3, 4) were filled with HRP during the course of in vivo experiments (Somogyi et al., 1983; Kisvarday et al., 1985; Douglas et al., 1989). The 3-dimensional coordinates and diameter of the dendritic tree were sampled by a computer-assisted method. Appropriate precautions were taken to measure, minimize, and compensate for tissue shrinkage and digitization errors. Each branch of the digitized dendritic tree was replaced by a single equivalent cylinder. The dimensions of the cylinder were obtained by combining all of the measurements along a branch to obtain the 

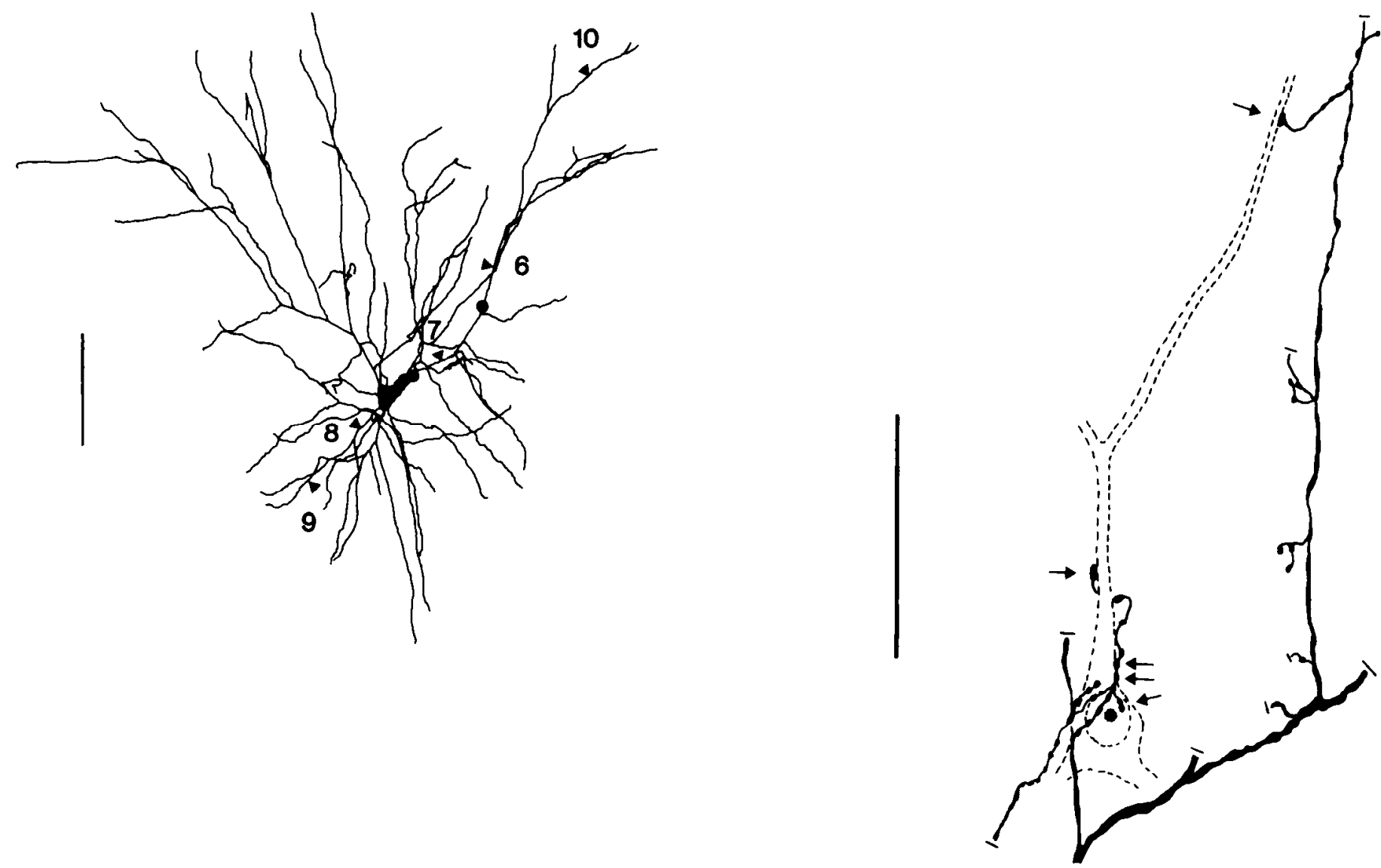

Figure 4. A, Computer plot of a reconstructed layer $2 / 3$ pyramidal cell. The filled circles indicate the locations of 8 basket cell synapses obtained from the reconstruction shown in $B$. Four of the 8 synapses were located directly on the soma. Numbered arrowheads indicate the locations of spines that received excitatory inputs. This cell is more compact than the layer 5 pyramidal cell in Figure $3 A$. The diameter of the apical dendrite is $3.4 \mu \mathrm{m}$ leaving the soma but is reduced to $2.2 \mu \mathrm{m}$ at synapse 7 and $1.4 \mu \mathrm{m}$ at synapse 6 . Scale bar, $100 \mu \mathrm{m}$. $B$. Afferent of layer $3 / 4$ basket cell making synaptic contact with a layer $2 / 3$ pyramidal cell. Redrawn from figure $4 b$ of Somogyi et al. (1983), with permission. The arrows point to the synaptic contacts that were transposed to the cell shown in $A$. Scale bar, $50 \mu \mathrm{m}$.

total length and average diameter of the cylinder. In this way, the original neuron was reduced to a set of connected cylinders. The most distal cylinders were terminated by sealed ends. The soma was assumed to be a prolate ellipsoid and was represented electrically as a lumped $\mathrm{RC}$ circuit. The major and minor axes of the ellipsoid were measured from the largest coronal cross section through the soma.

The transfer resistances $K_{i j}$ between arbitrary points on the reduced neuron are computed by a method similar to that described by Koch and Poggio (1985). We only examine the behavior of the cell for stationary or very slowly varying synaptic input. Representative locations of the putative inhibitory synapses of basket cells on superficial and deep pyramidal cells are obtained from the literature. It is clear that a single pyramidal cell receives convergent input from perhaps tens of basket cells (Martin et al., 1983). Kisvarday et al. (1986) have reported the detailed reconstruction of the terminations of an HRP-filled layer $5 / 6$ basket cell onto a layer 5 pyramidal neuron. Some of these synaptic contacts were confirmed by electron microscopy. We measured the locations of the basket cell synapses made on their pyramidal neuron $\mathbf{P} 3$, as presented in figure 3 of Kisvarday et al. (1986). The relevant terminations, redrawn from their figure, are presented here in Figure $3 B$. We measure the displacements from the soma of the synapses indicated by arrows in Figure $3 B$ and assume similar distances for the locations of inhibition on our measured layer 5 pyramidal cell. Four inhibitory synapses are applied to the soma. All excitatory inputs were applied via spines. The locations of these are chosen for their interest value. For example, inputs 14 and 15 are close in and far out on a typical basal dendrite; 17 is at the distal end of the apical dendrite; inputs 19 and 20 can be programmed to share their spines with inhibitory synapses, and so on.

The terminations of a layer $3 / 4$ basket cell onto a layer $2 / 3$ pyramidal cell are obtained from similar data reported by Somogyi et al. (1983). The relevant portion of their figure 10a is presented here as Figure $4 B$. Again, 4 inhibitory synapses are located at the cell body. The superficial pyramidal cell we use in this simulation differs from pyramidal cells in other layers in that it has 2 apical dendrites, i.e., both have total dendritic lengths and diameters that are considerably larger than that of the basal dendrites. It is not unusual for the apical dendrites of layer $2 / 3$ pyramidal cells to bifurcate close to the soma.

We usually assume that synaptic activation evokes a conductance change at all of the inhibitory synapses formed by the basket cell axon, while we consider both single excitatory synapses as well as excitatory groups firing simultaneously. Simulations consist of computing $K_{i j}$ for various combinations of $i$ and $j$ for values of $R_{m}$ either equal to 10,000 or $40,000 \Omega \mathrm{cm}^{2}$. $R_{i}$ is always $100 \Omega \mathrm{cm}$. The $K_{i j}$ matrix, a list of synaptic conductances and reversal potentials, and an optional exogenous 
current injection at the soma, are then submitted to a second program that solves the generalization of Eq. (8) for $n$ simultaneous, stationary synaptic inputs. Typical values for the input resistance throughout the 2 pyramidal cells as well as the electrotonic distance from these locations to the cell body are given in Table 1. The input resistances we obtain for $R_{m}=10,000 \Omega$ $\mathrm{cm}^{2}$ reflect the range of values measured in cortical slice preparations, while the higher values computed for $40,000 \Omega \mathrm{cm}^{2}$ are consistent with those found in vivo by Douglas et al. (1988).

There is considerable evidence that cortical inhibition depends on both GABA $A$ and $\mathrm{GABA}_{\mathrm{B}}$ receptors (Dutar and Nicoll, 1988; for review, see Douglas and Martin, 1989). The GABA effect is thought to be mediated via chloride conductance channels located on the cell body and proximal dendrites. The $\mathrm{GABA}_{\mathrm{B}}$ effect is mediated by potassium conductance channels on the dendrites (Douglas and Martin, 1989). We therefore test 2 models of inhibition. The Chloride model assumes that all inhibitory synapses activate chloride conductances (of amplitude $g_{\mathrm{Cl}}$ ), with a reversal potential identical to the resting potential, i.e., $E_{i}=0 \mathrm{mV}$, i.e., silent inhibition. The Mixed model assumes that only the somatic synapses are mediated by chloride conductances, while all dendritic synapses are mediated by potassium conductances (of amplitude $g_{\mathrm{K}}$ ). The potassium reversal potential is set at $E_{i}=-20 \mathrm{mV}$ (with respect to resting potential). We usually test 3 values of chloride conductance $g_{\mathrm{Cl}}, 0.1,1.0$, and $10.0 \mathrm{nS}$, while the potassium conductance $g_{\mathrm{K}}$ is usually held constant at $0.1 \mathrm{nS}$, but is sometimes as much as $10 \mathrm{nS}$.

Excitatory inputs are applied only onto spines, modeled by interposing a resistance, representing the thin spine neck, between the synaptic conductance change and the dendrite. We use a neck resistance of $100 \mathrm{M} \Omega$ for $R_{m}=10,000 \Omega \mathrm{cm}^{2}$ and $400 \mathrm{M} \Omega$ for $R_{m}=40,000 \Omega \mathrm{cm}^{2}$. Little is known about the amplitudes of excitatory synaptic conductance changes. An analysis of voltage-clamp data from cultured hippocampus pyramidal cell yields a kainate-quisqualate-mediated conductance increase of $0.5 \mathrm{nS}$ and much less for the NMDA receptor-mediated conductance increase (for a review, see Brown et al., 1988). Most of our computations use excitatory conductances of $0.1 \mathrm{nS}$, but values up to $10 \mathrm{nS}$ are also tested. The excitatory synaptic reversal potential $E$ is $60 \mathrm{mV}$.

In order to judge the effectiveness of inhibition in reducing EPSPs, we introduce the dimensionless $M$ factor as

$$
M=\frac{V_{e+i}-V_{i}}{V_{e}}
$$

that is, the ratio of the amplitude of the inhibited EPSP at the soma $\left(V_{p+i}\right)$ minus the amplitude of the IPSP alone $\left(V_{i}\right)$ to the amplitude of the uninhibited somatic EPSP $\left(V_{e}\right)$. The $M$ factor is the effective multiplication factor achieved by the inhibition and is independent of any membrane polarization induced by the inhibition. A low $M$ factor implies that the interaction between the inhibition and excitation is highly nonlinear, while $M=1$ implies perfect linearity (because $V_{e+i}=V_{e}+V_{i}$ ). In the case of silent inhibition, $V_{i}=0$ and $M=1 / F$, where $F$ is the $F$-factor introduced by Koch ct al. (1982). For strong hyperpolarizing inhibition $\left(E_{i}<0\right), M$ can exceed 1 .

\section{Results}

\section{Idealized neuron}

Figure 5 shows the somatic input conductance $G_{s s}^{*}$ measured with an electrode in the cell body of the idealized neuron for
Table 1. Input resistance $\left(K_{i i}\right)$ and electrotonic distance $X$ for several sites $^{a}$

\begin{tabular}{|c|cc|cc|}
\hline & \multicolumn{2}{|c|}{$K_{i i}$} & \multicolumn{2}{c|}{$X=\ell / \lambda$} \\
$R_{m}$ & 10,000 & 40,000 & 10,000 & 40,000 \\
\hline soma & 23.27 & 81.03 & 0.00 & 0.00 \\
19 & 26.99 & 83.96 & 0.14 & 0.07 \\
18 & 30.14 & 86.92 & 0.25 & 0.12 \\
16 & 84.90 & 153.08 & 0.73 & 0.37 \\
\hline soma & 56.80 & 210.03 & 0.00 & 0.00 \\
7 & 62.49 & 215.70 & 0.06 & 0.03 \\
6 & 98.63 & 254.82 & 0.21 & 0.11 \\
10 & 468.63 & 661.34 & 0.69 & 0.35 \\
\hline
\end{tabular}

a On the cell body and on the dendrite just below the synapses indicated by number (see Figs. $3 A$ and $4 A$ ) in the layer 5 pyramidal cell (top part of table) and the layer $2 / 3$ pyramidal cell (lower part) for 2 values of membrane resistance, $R_{m}$. Note the electrotonic compactness of both cells. To obtain the input resistance at the spine head, add $100 \mathrm{M} \Omega$ for the $R_{m}=10,000$ and $400 \mathrm{M} \Omega$ for the $40,000 \Omega \mathrm{cm}^{2}$ case.

various locations of a single excitatory synapse with an associated constant increase in the membrane conductance $g_{i}$. Notice that $G_{s s}^{*}$ for synapses located directly at the soma, i.e., for $l=$ 0 , reflects the sum of the unperturbed input conductance $G_{s s}=$ $6.71 \mathrm{nS}$ and $g_{i}$. The experimentally resolvable conductance increase for experiments of the kind described by Douglas et al. (1988) is about $20 \%$ of the somatic input conductance, i.e., a conductance increase $\Delta G_{s s}$ can be detected if $\Delta G_{s s} / G_{s s}^{*}>0.2$. Thus, in practice, a single $10 \mathrm{nS}$ input on the main dendrite is not detectable beyond approximately $0.6 \lambda$ (Fig. $5 A$ ). The distance beyond which a synaptic input will remain hidden (using present technology) decreases if the intracellular electrode causes significant injury to the cell, thereby adding a leakage conductance. In this case, we require $\Delta G_{s s} /\left(G_{s s}^{*}+G_{\text {leak }}\right)>0.2$ for an input to be seen [see Eq. (20)].

Figure 6 illustrates how transient synaptic conductance changes affect $G_{s s}^{*}$ (compare this curve with Fig. 6 in Rall, 1967). The large size of the conductance inputs can be judged by the size of the evoked EPSP (Fig. 6A). As predicted, the change in input conductance induced by the transient inputs is less than that induced by stationary ones (compare Fig. $6 B$ with $5 A$ ). However, the difference between the 2 is remarkably small, considering that the rise time of the conductance inputs is only $20 \%$ of the membrane time constant ( $2 \mathrm{vs} 10 \mathrm{msec})$.

The behavior of the short-pulse method for measuring somatic input conductance, $G_{\text {in }}$, via Eq. (24), is illustrated in Figure 7. The voltage response in the soma, evoked by injecting a 0.1 nA current pulse of variable duration $T$, is plotted in Figure $7 \mathrm{~A}$. As discussed above, integration over a short-duration pulse results in an underestimate of the input resistance (Fig. $7 B$ ), and therefore in an overestimate of the input conductance. However, if the response is integrated over a sufficiently long interval, the true input conductance is eventually recovered. For sufficient convergence, the duration of the current step must be several times that of the membrane time constant (here, $10 \mathrm{msec}$ ), so that the membrane potential can settle to its new value.

So far, we have considered the change in somatic input conductance in response to a single synaptic input. We prove in the analytical section of this paper that the interaction of several 
Figure 5. A, Somatic input conductance, $G_{s s}^{*}$, after application of a single excitatory steady-state synaptic input on the main dendrite of our idealized neuron as a function of the electrotonic distance $x / \lambda$ between the synapse and the soma. The 3 curves correspond to $g_{1}=1,5$, and $10 \mathrm{nS}$, respectively. In this and the following figures, the solid arrow points towards the value of the somatic input conductance without input, $G_{w}=6.71 \mathrm{nS}$, while the stippled line indicates the lower limit on the experimentally measurable input conductance change ( $20 \%$ of $G_{*}$ ). B, $G_{*}^{*}$ for a stationary synaptic input on the main dendrite (upper curve) and on the secondary dendritic branches (lower curve); $g_{i}=10 \mathrm{nS}$ and $E=91 \mathrm{mV}$.
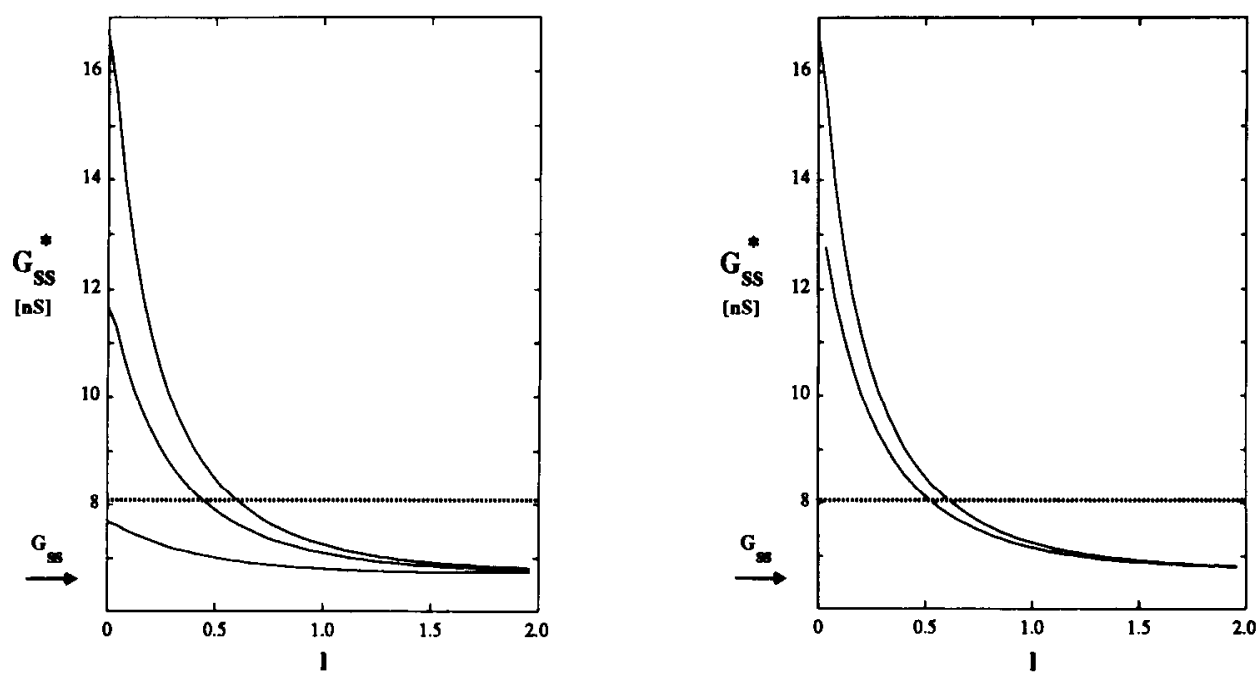

synaptic inputs will reduce the resultant change in input conductance to less than the sum of the conductance changes to the individual synaptic inputs. Because of asynchronous activation of the synaptic inputs, $G_{s s}^{*}$ will be further reduced. We examine these effects in the response of our idealized cell to multiple asynchronous and transient excitatory and inhibitory synapses. The results are illustrated in Figure 8 . Activation of 13 excitatory synapses with $g_{\text {peak }}=2 \mathrm{nS}$ and $t_{\text {peak }}=2 \mathrm{msec}$ (top trace in Fig. $8 A$ and bottom trace in $8 B$ ) depolarizes the cell to about $44 \mathrm{mV}$ relative to the cell's resting potential but increases the somatic input conductance $G_{s s}^{*}$ by only about $3 \mathrm{nS}$. Activation of an additional 13 inhibitory synapses with $g_{\text {peak }}=5 \mathrm{nS}$ and $t_{\text {peak }}=$ $5 \mathrm{msec}$ reduces the potential from $44 \mathrm{mV}$ (relative to the resting potential) to about $16 \mathrm{mV}$ and increases $G_{s s}^{*}$ to about $18 \mathrm{nS}$. Thus, although in the latter case 26 synapses with peak conductance changes between 2 and $5 \mathrm{nS}$ are all activated within the first $25 \mathrm{msec}$ following the onset of the stimulus, due to temporal dispersion and to the nonlinearity alluded above, the somatic input conductance only increases by about $11.2 \mathrm{nS}$ ! Note that, as expected, $G_{s,}^{*}$ does not depend on the reversal potential of the synapse.

\section{Cortical pyramidal cells}

In these simulations we use the detailed morphology of cortical neurons-and in particular the location of identified synapsesto evaluate the magnitude of the conductance change in the soma of a pyramidal cell due to input from a single basket cell.
Tables $2-4$ summarize the results. Table 2 lists the percentage conductance change, visibility, and the $M$ factor for one representative excitatory input in each case. This input is given to synapse 18 on the layer 5 pyramidal cell and to synapse 6 on the layer $2 / 3$ pyramidal cell. Table 3 gives more comprehensive results for the layer 5 pyramidal cell for just a few of the cases summarized in Table 2, while Table 4 provides this information for the superficial pyramidal cell.

Table 2 shows that the visibility from the soma of the conductance change evoked by the single basket afferent is generally high. The visibility is smallest $(65 \%)$ for the layer 5 pyramidal neuron, in the case that individual chloride-mediated synaptic conductances (silent inhibition) are large. Conductance changes in the Mixed model are almost entirely visible, even when the chloride synaptic conductance is large. In fact, for this model, the visibility improves with increasing $g_{\mathrm{Cl}}$ (see L5Pyr). This improvement is due to the relative contributions to the total input conductance change provided by the constant $0.1 \mathrm{nS}$ potassium conductance increase $g_{\mathrm{K}}$ on the dendrites and the increasing $g_{\mathrm{Cl}}$ at the soma. Because the chloride-mediated synapses are located on the soma, they contribute a progressively increasing and completely visible fraction of the conductance change. On the other hand, the partially hidden (but constant) potassium-mediated synapses out in the dendritic tree provide a progressively smaller fraction of the total conductance change recorded at the soma.

The $M$ factor decreases with increasing inhibitory synaptic
Figure 6. A, The somatic EPSP in response to a single, transient excitatory synapse at various locations along the main dendrite. $t_{\text {peak }}=2 \mathrm{msec}, g_{\text {pak }}=10$ $\mathrm{nS}$, and $E=91 \mathrm{mV}$. The total duration of $g(t)$ is approximately $16 \mathrm{msec}$. $B$, The observed somatic input conductance for 3 different values of $g_{\text {reak }}: 1,5$, and 10 $\mathrm{nS}$ as a function of electrotonic distance between the synapse and the soma. This plot should be compared with $G_{s s}^{*}$ in Figure $5 A$ for stationary input.
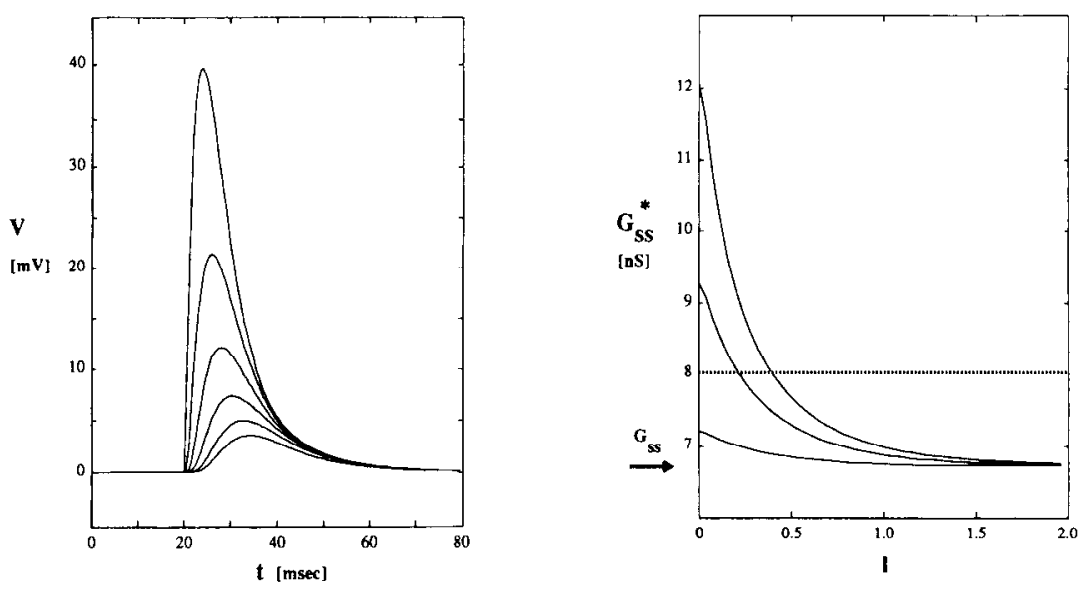


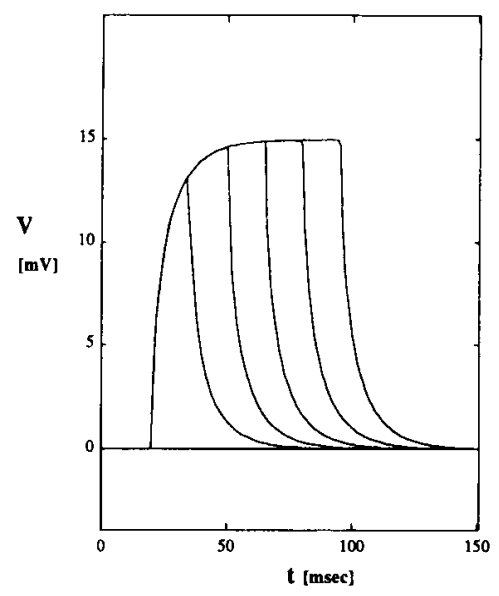

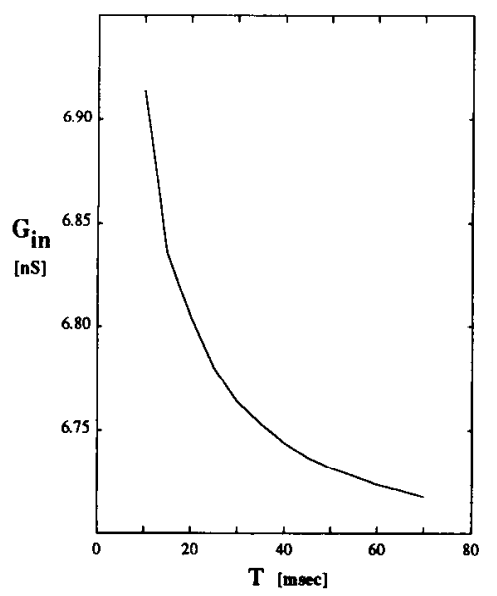

Figure 7. Short-pulse method used to estimate the input conductance (Barrett and Barrett, 1976). A current step of constant amplitude $(0.1 \mathbf{n A})$ is injected for a variable duration $T$ and the voltage response (shown in $A$ ) is integrated following Eq. (24). $B$, Resultant values of input conductance $G_{\text {in }}$ as a function of the duration $T$ of the current step. For short pulses this method consistently overestimates the input conductance. If $T>\tau_{m}, G_{\text {in }}$ converges to the correct value $G_{s s}$. conductance (Tables 2-4). This decrease is greater for the Chloride model than for the Mixed model and is most marked for the cases with high $R_{m}$. In all cases, a reduction in $M$ is associated with an increase in the somatic input conductance. For example, attenuation of excitation to less than about $70 \%$ of its control value is associated with an increase in $G_{s s}^{*}$ of at least $30 \%$. Thus, for the models of cortical inhibition that we investigate, significant inhibition is always associated with an increase in somatic input conductance that is sufficiently large to be detectable by the methods employed by Douglas et al. (1988). The $M$ factor of the Mixed model decreased with increasing $g_{\mathrm{C} l}$ because the inhibitory action depends largely on its chloride component to achieve attenuation of the EPSP. However, the $g_{\mathrm{K}}$ component will contribute to the efficacy of inhibition by its hyperpolarizing effect, as described below.

These results are not substantially affected by moving 2 of the inhibitory synapses onto spines that were shared by excitatory inputs (Figs. $3 A, 4 A$, Table 3 ). This is because the inhibitory synapses on spines do not act in isolation. They always act in concert with the dendritic and somatic terminations that arise from the same inhibitory afferent. Consequently, the effects in the soma are dominated by the nonspinous terminations.

\section{Nonanatomical synaptic arrangements}

The inhibitory synapses on the layer 5 pyramidal cell form 2 anatomical groups: those clustered about the soma and proximal apical dendrite and those that are applied to the more distal apical dendrite as it courses through layer 4 of the cortex. These groupings may have functional significance. Therefore, in a departure from the strict anatomical model specified above, we investigate the case in which some inhibitory afferents are assumed to activate only the dendritic synapses. We assume that these synapses are potassium-mediated (with $E_{\mathrm{K}}=-20 \mathrm{mV}$ ). The excitatory input is a $10 \mathrm{nS}$ conductance increase applied to spines 18 and 20 (Fig. $3 \mathrm{~A}$ ). This large input generates a somatic depolarization of $13.8 \mathrm{mV}$. We test this modified model over a range of values of $g_{\mathrm{K}}$, seeking a value that might cause a significant drop in excitatory voltage, without inducing too large a change in the neuronal input conductance. The optimal solution is $g_{\mathrm{K}}=0.4 \mathrm{nS}$. This reduces the excitatory depolarization to $7.93 \mathrm{mV}$, and is associated with a $24.7 \%$ increase in somatic input conductance, approaching the practical dctcction limits encountered by Douglas et al. (1988). The visibility of this conductance change is $69 \%$ and the $M=0.88$. Increasing the synaptic reversal potential to $E_{\mathrm{K}}=-40 \mathrm{mV}$ reduces the EPSP to $4.6 \mathrm{mV}$, a reduction of $9.2 \mathrm{mV}$. This is associated with a $24.7 \%$ increase in $G_{s s}^{*}$, a visibility of $69 \%$ and an $M$ factor of 0.94 , indicating relatively linear inhibition (for $g_{\mathrm{K}}=0.4 \mathrm{nS}$ ).

In another departure from the known anatomy of cortical inhibitory interneurons, we tested the visibility of inhibition located only onto spines. Thus, for the layer 5 cell we assume that inhibition either shares spines 14-20 (Fig. 3A) with excitation or is located on the dendrite, just at the base of these spines. Table 5 illustrates the somewhat surprising result that
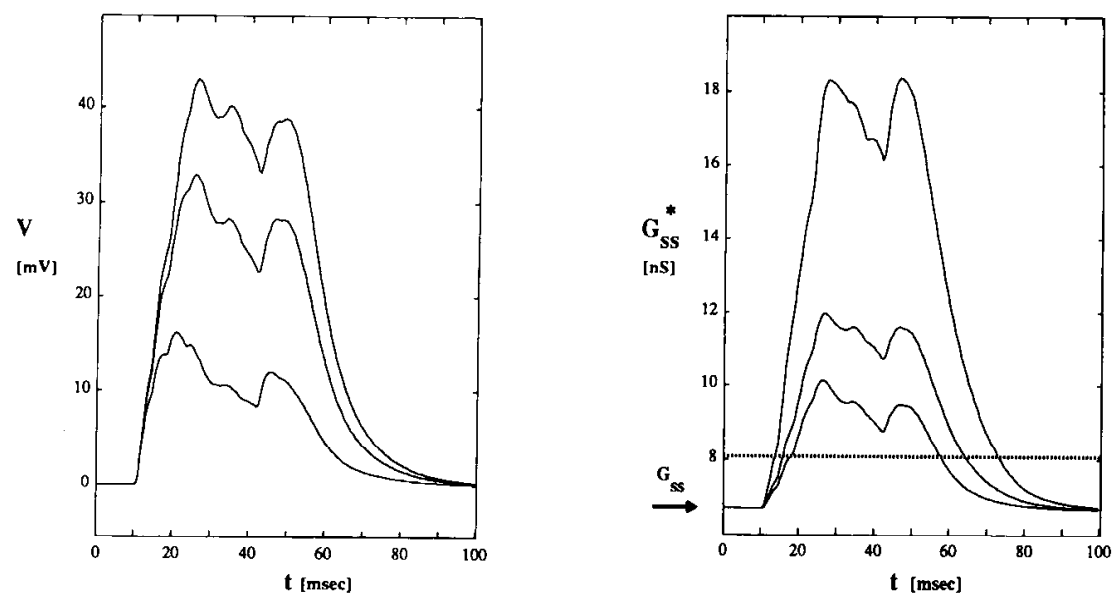

Figure 8. A, Somatic membrane potential for multiple synaptic inputs on the dendritic tree. Thirteen excitatory synapses are distributed on the secondary dendrites at a distance of $0.3-0.5 \lambda$ from the soma, with $g_{\text {peak }}=10 \mathrm{nS}, t_{\text {peak }}$ $=2 \mathrm{msec}$, and $E=91 \mathrm{mV}$. Thirteen silent inhibitory synapses are interspersed between excitation on the main dendrite with $g_{\text {pcak }}=0$ (top curve), 1 (middle curve), and $5 \mathrm{nS}$ (bottom curve), $t_{\text {peak }}=5 \mathrm{msec}$ and $E=0 \mathrm{mV}$. $B$, The resulting somatic input conductance $G_{\mathrm{v}}^{*}$ in the presence of excitation and no inhibition (bottom curve), $1 \mathrm{nS}$ (middle), and $5 \mathrm{nS}$ inhibition (top curve). 
Table 2. Inhibitory effects of basket cell activation on pyramidal neurons in visual cortex of the cat

L5Pyr: $\mathrm{Cl} R_{m}=10,000 \Omega \mathrm{cm}^{2}$

\begin{tabular}{|c|c|c|c|c|c|c|}
\hline$g_{C l}$ & $K_{s s}$ & $\% \Delta K_{s s}$ & $G_{s s}$ & $\% \Delta G_{s s}$ & $\Gamma$ & $M$ \\
\hline 0.0 & 23.27 & 0.0 & 42.97 & 0.0 & - & 1.00 \\
\hline 0.1 & 22.58 & -3.0 & 44.29 & 3.1 & 0.83 & 0.96 \\
\hline 1.0 & 17.94 & -22.9 & 55.74 & 29.7 & 0.80 & 0.73 \\
\hline 10.0 & 6.83 & -70.6 & 146.41 & 240.7 & 0.65 & 0.15 \\
\hline
\end{tabular}

L5Pyr: Mixed $R_{m}=10,000 \Omega \mathrm{cm}^{2} g_{K}=0.1 \mathrm{nS}$

\begin{tabular}{|c|c|c|c|c|c|c|}
\hline$g_{C l}$ & $K_{s s}$ & $\% \Delta K_{s s}$ & $G_{s s}$ & $\% \Delta G_{s s}$ & $\Gamma$ & $M$ \\
\hline 0.0 & 23.27 & 0.0 & 42.97 & 0.0 & - & 1.00 \\
\hline 0.1 & 22.58 & -3.0 & 44.29 & 3.1 & 0.83 & 0.97 \\
\hline 1.0 & 20.88 & -10.2 & 47.89 & 11.4 & 0.95 & 0.90 \\
\hline 10.0 & 11.92 & -48.8 & 83.89 & 95.2 & 1.00 & 0.51 \\
\hline
\end{tabular}

L5Pyr: $\mathrm{Cl} R_{m}=40,000 \Omega \mathrm{cm}^{2}$

\begin{tabular}{|c|c|c|c|c|c|c|}
\hline$g_{C l}$ & $K_{s s}$ & $\% \Delta K_{s s}$ & $G_{s s}$ & $\% \Delta G_{s s}$ & $\Gamma$ & $M$ \\
\hline 0.0 & 81.03 & 0.0 & 12.34 & 0.0 & - & 1.00 \\
\hline 0.1 & 72.33 & -10.7 & 13.83 & 12.0 & 0.93 & 0.88 \\
\hline 1.0 & 37.72 & -53.4 & 26.51 & 114.8 & 0.89 & 0.42 \\
\hline 10.0 & 8.23 & -89.8 & 121.51 & 888.5 & 0.68 & 0.05 \\
\hline
\end{tabular}

L5Pyr: Mixed $R_{m}=40,000 \Omega \mathrm{cm}^{2} g_{K}=0.1 \mathrm{nS}$

\begin{tabular}{|c|c|c|c|c|c|c|}
\hline$g_{C l}$ & $K_{s s}$ & $\% \Delta K_{s s}$ & $G_{s s}$ & $\% \Delta G_{s s}$ & $\Gamma$ & $M$ \\
\hline 0.0 & 81.03 & 0.0 & 12.34 & 0.0 & - & 1.00 \\
\hline 0.1 & 73.32 & -10.7 & 13.83 & 12.0 & 0.93 & 0.83 \\
\hline 1.0 & 57.38 & -29.1 & 17.43 & 41.2 & 0.98 & 0.72 \\
\hline 10.0 & 18.71 & -76.9 & 53.45 & 333.0 & 1.00 & 0.23 \\
\hline
\end{tabular}

L2/3Pyr: Cl $R_{m}=10,000 \Omega \mathrm{cm}^{2}$

\begin{tabular}{|c|c|c|c|c|c|c|}
\hline$g_{C l}$ & $K_{s s}$ & $\% \Delta K_{s s}$ & $G_{s s}$ & $\% \Delta G_{s s}$ & $\Gamma$ & $M$ \\
\hline 0.0 & 56.86 & 0.0 & 17.59 & 0.0 & - & 1.00 \\
\hline 0.1 & 54.46 & -4.2 & 18.36 & 4.4 & 0.96 & 0.96 \\
\hline 1.0 & 39.51 & -39.5 & 25.31 & 43.9 & 0.97 & 0.67 \\
\hline 10.0 & 10.88 & -80.9 & 91.91 & 422.5 & 0.93 & 0.13 \\
\hline
\end{tabular}

L2/3Pyr: Mixed $R_{m}=10,000 \Omega c m^{2} g_{K}=0.1 n S$

\begin{tabular}{|c|c|c|c|c|c|c|}
\hline$g_{C l}$ & $K_{s s}$ & $\% \Delta K_{s s}$ & $G_{s s}$ & $\% \Delta G_{s s}$ & $\Gamma$ & $M$ \\
\hline 0.0 & 56.86 & 0.0 & 17.59 & 0.0 & - & 1.00 \\
\hline 0.1 & 54.46 & -4.2 & 18.36 & 4.4 & 0.98 & 0.96 \\
\hline 1.0 & 45.53 & -19.9 & 21.96 & 24.9 & 1.00 & 0.80 \\
\hline 10.0 & 17.25 & -69.7 & 57.97 & 229.6 & 1.00 & 0.31 \\
\hline
\end{tabular}

L2/3Pyr: $\mathrm{Cl} R_{m}=40,000 \Omega \mathrm{cm}^{2}$

\begin{tabular}{|c|c|c|c|c|c|c|}
\hline$g_{C l}$ & $K_{s s}$ & $\% \Delta K_{s s}$ & $G_{s s}$ & $\% \Delta G_{s s}$ & $\Gamma$ & $M$ \\
\hline 0.0 & 210.03 & 0.0 & 4.76 & 0.0 & - & 1.00 \\
\hline 0.1 & 180.05 & -14.2 & 5.55 & 16.7 & 0.99 & 0.86 \\
\hline 1.0 & 79.12 & -62.3 & 12.64 & 165.5 & 0.99 & 0.36 \\
\hline 10.0 & 12.49 & -94.0 & 80.06 & 1581.6 & 0.94 & 0.04 \\
\hline
\end{tabular}

L2/3Pyr: Mixed $R_{m}=40,000 \Omega \mathrm{cm}^{2} g_{K}=0.1 \mathrm{nS}$

\begin{tabular}{|c|c|c|c|c|c|c|}
\hline$g_{C l}$ & $K_{s s}$ & $\% \Delta K_{s s}$ & $G_{s s}$ & $\% \Delta G_{s s}$ & $\Gamma$ & $M$ \\
\hline 0.0 & 210.03 & 0.0 & 4.76 & 0.0 & - & 1.00 \\
\hline 0.1 & 180.05 & -14.2 & 5.55 & 16.7 & 0.99 & 0.88 \\
\hline 1.0 & 109.24 & -47.9 & 9.15 & 92.3 & 1.00 & 0.53 \\
\hline 10.0 & 22.14 & -89.4 & 45.17 & 848.6 & 1.00 & 0.11 \\
\hline
\end{tabular}

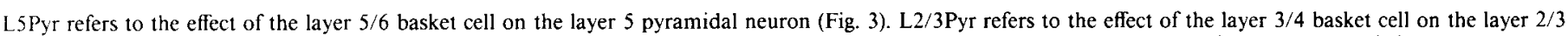

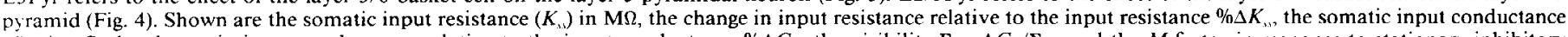

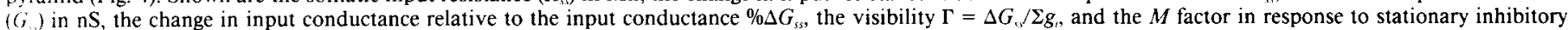

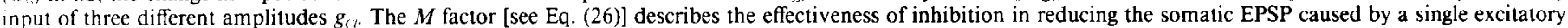

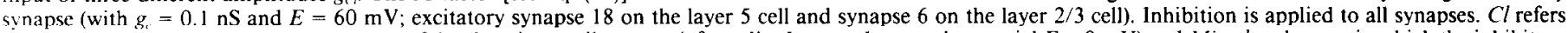

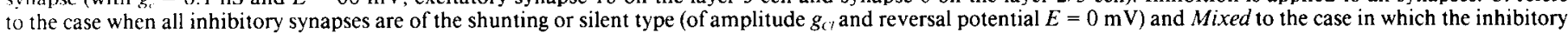

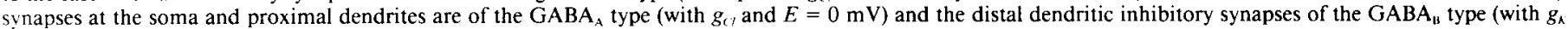
and $E=-20 \mathrm{mV}$ ). $R_{m}$ denotes the 2 different values of the specific membrane resistance.

for a relatively small excitatory conductance change $\left(g_{e}=0.1\right.$ $\mathrm{nS}$ ) applied to all synapses, inhibition is (1) not very effective in reducing the somatic EPSP, and (2) if large enough (i.e., $>1$ $\mathrm{nS}$ in the $R_{m}=40,000 \Omega \mathrm{cm}^{2}$ case) is quite visible from the cell body. The fact that inhibition is not more effective in reducing excitation is due to the very small size of the excitatory input (small relative to the input resistance at the spine). For larger values of $g_{c}$, inhibition becomes more effective. As we noted above, our definition of the $M$ factor in Eq. (26) is identical to $1 / F$ for shunting inhibition, where $F$ is the ratio of somatic EPSP without inhibition to the somatic potential in the presence of inhibition (Koch et al., 1982). If inhibition and excitation share the same location, we have $F=1+g_{i} K_{i i} /\left(1+g_{e} K_{i i}\right)$, with $K_{i i}$ the input resistance of the spine. As long as $g_{e} K_{i} \ll 1$, we arrive at $M=1 / F \approx 1 /\left(1+g_{i} K_{i i}\right)$. We wish to emphasize at this point that such a specific innervation of spines by inhibition as postulated here has not been reported.

\section{Discussion}

Assumptions

This study examines the common experimental problem of interpreting synaptic events that occur at distal dendritic sites but are observed via a microelectrode located in the cell body. The principal assumption underlying all our results is that the neuronal membrane responds linearly within the voltage domain of interest (approximately $\pm 10 \mathrm{mV}$ around the resting potential). If significant membranc nonlincaritics arc activated by the synaptic input, such as the high-threshold calcium conductance 
Table 3. Interaction of excitatory and inhibitory effects in our layer 5 pyramidal neuron in visual cortex of the cat

\begin{tabular}{|c|c|c|c|c|c|c|c|c|c|c|c|c|c|}
\hline \multicolumn{2}{|l|}{ MODFI } & \multicolumn{2}{|l|}{$\mathrm{Cl}$} & \multicolumn{2}{|l|}{ Mixed } & \multicolumn{2}{|l|}{$\mathrm{Cl}$} & \multicolumn{2}{|l|}{$\mathrm{Cl}$} & \multicolumn{2}{|l|}{ Mixed } & \multicolumn{2}{|l|}{ Mixed } \\
\hline$R_{m}$ & & \multicolumn{2}{|c|}{10,000} & \multicolumn{2}{|l|}{10,000} & \multicolumn{2}{|l|}{40,000} & \multicolumn{2}{|c|}{40,000} & \multicolumn{2}{|l|}{40,000} & \multicolumn{2}{|l|}{40,000} \\
\hline$g_{e}$ & & \multicolumn{2}{|l|}{0.1} & \multicolumn{2}{|l|}{0.1} & \multicolumn{2}{|l|}{0.1} & \multicolumn{2}{|l|}{10.0} & \multicolumn{2}{|l|}{0.1} & \multicolumn{2}{|l|}{1.0} \\
\hline$g_{K}$ & & \multicolumn{2}{|l|}{-} & \multicolumn{2}{|l|}{0.1} & \multicolumn{2}{|l|}{-} & - & & 0.1 & & 1.0 & \\
\hline input & $g_{C l}$ & $V_{s}$ & $\mathrm{M}$ & $V_{s}$ & $\mathrm{M}$ & $V_{s}$ & $\mathrm{M}$ & $V_{s}$ & $\mathrm{M}$ & $V_{s}$ & $\mathrm{M}$ & $V_{s}$ & $\mathrm{M}$ \\
\hline nil & 0.0 & 0.00 & & 0.00 & & 0.00 & & 0.00 & & 0.00 & & 0.00 & \\
\hline & 0.1 & 0.00 & & -0.47 & & 0.00 & & 0.00 & & -1.64 & & -9.28 & \\
\hline & 1.0 & 0.00 & & -0.44 & & 0.00 & & 0.00 & & -1.30 & & -8.02 & \\
\hline & 10.0 & 0.00 & & -0.25 & & 0.00 & & 0.00 & & -0.43 & & -3.40 & \\
\hline 14 & 0.0 & 0.14 & & 0.14 & & 0.46 & & 8.19 & & 0.46 & & 3.25 & \\
\hline & 0.1 & 0.13 & 0.97 & -0.33 & 0.98 & 0.41 & 0.89 & 7.42 & 0.91 & -1.22 & 0.92 & -7.21 & 0.64 \\
\hline & 1.0 & 0.11 & 0.77 & -0.31 & 0.90 & 0.22 & 0.47 & 4.11 & 0.50 & -0.97 & 0.72 & -6.26 & 0.54 \\
\hline & 10.0 & 0.04 & 0.29 & -0.18 & 0.51 & 0.05 & 0.10 & 0.95 & 0.12 & -0.32 & 0.23 & -2.69 & 0.22 \\
\hline 15 & 0.0 & 0.12 & & 0.12 & & 0.44 & & 5.37 & & 0.44 & & 2.66 & \\
\hline & 0.1 & 0.12 & 0.97 & -0.35 & 0.98 & 0.39 & 0.90 & 4.84 & 0.90 & -1.24 & 0.92 & -7.60 & 0.63 \\
\hline & 1.0 & 0.09 & 0.77 & -0.33 & 0.90 & 0.21 & 0.47 & 2.62 & 0.49 & -0.99 & 0.72 & -6.26 & 0.66 \\
\hline & 10.0 & 0.04 & 0.30 & -0.19 & 0.51 & 0.05 & 0.10 & 0.59 & 0.11 & -0.32 & 0.23 & -2.83 & 0.22 \\
\hline 16 & 0.0 & 0.08 & & 0.08 & & 0.38 & & 6.08 & & 0.38 & & 2.56 & \\
\hline & 0.1 & 0.07 & 0.95 & -0.40 & 0.96 & 0.33 & 0.88 & 5.41 & 0.89 & -1.30 & 0.90 & -7.88 & 0.55 \\
\hline & 1.0 & 0.05 & 0.68 & -0.37 & 0.88 & 0.15 & 0.41 & 2.61 & 0.43 & -1.04 & 0.71 & -6.82 & 0.47 \\
\hline & 10.0 & 0.01 & 0.10 & -0.21 & 0.51 & 0.01 & 0.03 & 0.23 & 0.04 & -0.34 & 0.23 & -2.91 & 0.19 \\
\hline 17 & 0.0 & 0.05 & & 0.05 & & 0.31 & & 2.62 & & 0.31 & & 1.57 & \\
\hline & 0.1 & 0.05 & 0.96 & -0.43 & 0.96 & 0.28 & 0.88 & 2.32 & 0.88 & -1.36 & 0.90 & -8.44 & 0.54 \\
\hline & 1.0 & 0.03 & 0.69 & -0.39 & 0.88 & 0.13 & 0.41 & 1.08 & 0.41 & -1.08 & 0.71 & -7.30 & 0.46 \\
\hline & 10.0 & 0.01 & 0.10 & -0.23 & 0.50 & 0.01 & 0.04 & 0.09 & 0.04 & -0.35 & 0.23 & -3.11 & 0.19 \\
\hline 18 & 0.0 & 0.12 & & 0.12 & & 0.44 & & 7.77 & & 0.44 & & 3.07 & \\
\hline & 0.1 & 0.11 & 0.96 & -0.36 & 0.97 & 0.38 & 0.88 & 6.97 & 0.90 & -1.28 & 0.83 & -7.51 & 0.58 \\
\hline & 1.0 & 0.08 & 0.73 & -0.33 & 0.90 & 0.18 & 0.42 & 3.52 & 0.45 & -0.99 & 0.72 & -6.51 & 0.49 \\
\hline & 10.0 & 0.02 & 0.15 & -0.19 & 0.51 & 0.02 & 0.05 & 0.42 & 0.05 & -0.32 & 0.23 & -2.79 & 0.20 \\
\hline 19 & 0.0 & 0.12 & & 0.12 & & 0.45 & & 8.03 & & 0.45 & & 3.16 & \\
\hline & 0.1 & 0.12 & 0.97 & -0.35 & 0.98 & 0.40 & 0.89 & 7.23 & 0.90 & -1.23 & 0.94 & -7.36 & 0.60 \\
\hline & 1.0 & 0.09 & 0.73 & -0.35 & 0.69 & 0.20 & 0.44 & 3.78 & 0.47 & -0.98 & 0.73 & -6.43 & 0.50 \\
\hline & 10.0 & 0.02 & 0.19 & -0.19 & 0.52 & 0.03 & 0.06 & 0.59 & 0.07 & -0.32 & 0.24 & -2.75 & 0.21 \\
\hline 20 & 0.0 & 0.12 & & 0.12 & & 0.44 & & 7.96 & & 0.41 & & 3.14 & \\
\hline & 0.1 & 0.12 & 0.96 & -0.35 & 0.98 & 0.39 & 0.89 & 7.16 & 0.90 & -1.23 & 1.01 & -7.42 & 0.59 \\
\hline & 1.0 & 0.09 & 0.71 & -0.33 & 0.89 & 0.19 & 0.43 & 3.71 & 0.47 & -0.98 & 0.79 & -6.43 & 0.51 \\
\hline & 10.0 & 0.02 & 0.18 & -0.19 & 0.51 & 0.03 & 0.06 & 0.53 & 0.07 & -0.32 & 0.26 & -2.76 & 0.20 \\
\hline all & 0.0 & 0.73 & & 0.73 & & 2.80 & & 27.80 & & 2.80 & & 15.16 & \\
\hline & 0.1 & 0.71 & 0.96 & 0.24 & 0.97 & 2.49 & 0.89 & 26.00 & 0.94 & 0.93 & 0.92 & 0.79 & 0.66 \\
\hline & 1.0 & 0.54 & 0.73 & 0.22 & 0.90 & 1.25 & 0.45 & 16.34 & 0.59 & 0.74 & 0.73 & 0.69 & 0.57 \\
\hline & 10.0 & 0.15 & 0.21 & 0.13 & 0.51 & 0.19 & 0.07 & 3.23 & 0.12 & 0.25 & 0.24 & 0.31 & 0.25 \\
\hline
\end{tabular}

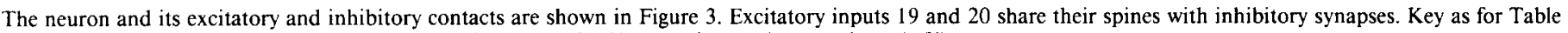
2 . Additional symbols: $g_{i}$, excitatory conductance increase (nS); $V_{s}$, somatic membrane voltage (mV).

found in the dendritic tree (and to some extent at the soma) in cat cortex (Stafstrom et al., 1982) linear cable theory no longer holds. In general, voltage-dependent membrane conductances in the CNS increase their value when the membrane is depolarized (for a review, see Llinás, 1988). Therefore, if synaptic input were to activate membrane nonlinearities, the resultant change in somatic input conductance would be larger than the change induced in the absence of the membrane nonlinearity. Because the principal motivation of our paper is to place a lower bound on the visibility of synaptic-induced inhibitory conductance changes, our results would not be affected. For contamination of the synaptic-induced conductance changes by mem- brane nonlinearities to be relevant here, one would have to argue that hyperpolarization activates an ionic current that decreases the membrane conductance. The resultant change in somatic input conductance would then be smaller than the change caused by synaptic input alone, thereby camouflaging the synaptic input. However, we are not aware of the existence of such a current in mammalian cortex.

We further constrain ourselves mainly to examining the behavior of neurons for stationary or very slowly varying synaptic input. This is a reasonable approximation, because typical stimuli used to evoke responses from neurons in visual cortex activate the neuron for considerably longer than its membrane 
Table 4. Interaction of excitatory and inhibitory effects in the layer $2 / 3$ pyramidal cell

\begin{tabular}{|c|c|c|c|c|c|c|c|c|c|c|c|c|c|}
\hline \multicolumn{2}{|l|}{ MODEL } & \multicolumn{2}{|l|}{$\mathrm{Cl}$} & \multicolumn{2}{|l|}{ Mixed } & \multicolumn{2}{|l|}{$\mathrm{Cl}$} & \multicolumn{2}{|l|}{$\mathrm{Cl}$} & \multicolumn{2}{|l|}{ Mixed } & \multicolumn{2}{|l|}{ Mixed } \\
\hline$R_{m}$ & & \multicolumn{2}{|c|}{10,000} & \multicolumn{2}{|c|}{10,000} & \multicolumn{2}{|c|}{40,000} & \multicolumn{2}{|l|}{40,000} & \multicolumn{2}{|l|}{40,000} & \multicolumn{2}{|l|}{40,000} \\
\hline$g_{e}$ & & \multicolumn{2}{|c|}{0.1} & \multicolumn{2}{|c|}{0.1} & \multicolumn{2}{|c|}{0.1} & \multicolumn{2}{|l|}{1.0} & \multicolumn{2}{|l|}{0.1} & \multicolumn{2}{|l|}{1.0} \\
\hline$g_{K}$ & & \multicolumn{2}{|l|}{-} & \multicolumn{2}{|l|}{0.1} & \multicolumn{2}{|l|}{-} & \multicolumn{2}{|l|}{-} & \multicolumn{2}{|l|}{0.1} & \multicolumn{2}{|l|}{1.0} \\
\hline input & $g_{C l}$ & $V_{s}$ & $\mathrm{M}$ & $V_{s}$ & $M$ & $V_{s}$ & $\mathrm{M}$ & $V_{s}$ & $M$ & $V_{s}$ & $\mathrm{M}$ & $V_{s}$ & $\mathrm{M}$ \\
\hline \multirow{4}{*}{ nil } & 0.0 & 0.00 & & 0.00 & & 0.00 & & 0.00 & & $\overline{0.00}$ & & 0.00 & \\
\hline & 0.1 & 0.00 & & -0.42 & & 0.00 & & 0.00 & & -1.43 & & -8.65 & \\
\hline & 1.0 & 0.00 & & -0.35 & & 0.00 & & 0.00 & & -0.87 & & -6.19 & \\
\hline & 10.0 & 0.00 & & -0.13 & & 0.00 & & 0.00 & & -0.18 & & -1.62 & \\
\hline 6 & 0.0 & 0.29 & & 0.29 & & 1.14 & & 7.35 & & 1.14 & & 7.35 & \\
\hline & 0.1 & 0.28 & 0.97 & -0.14 & 0.97 & 0.98 & 0.86 & 6.39 & 0.87 & -0.43 & 0.88 & -4.13 & 0.62 \\
\hline & 1.0 & 0.20 & 0.69 & -0.12 & 0.79 & 0.42 & 0.37 & 2.86 & 0.39 & -0.26 & 0.56 & -3.01 & 0.43 \\
\hline & 10.0 & 0.04 & 0.14 & -0.04 & 0.31 & 0.05 & 0.04 & 0.33 & 0.04 & -0.05 & 0.11 & -0.81 & 0.11 \\
\hline 7 & 0.0 & 0.33 & & 0.33 & & 1.18 & & 7.73 & & 1.18 & & 7.73 & \\
\hline & 0.1 & 0.31 & 0.94 & -0.11 & 0.94 & 1.01 & 0.86 & 6.74 & 0.87 & -0.39 & 0.88 & -3.7 & 0.64 \\
\hline & 1.0 & 0.22 & 0.67 & -0.09 & 0.79 & 0.44 & 0.38 & 3.13 & 0.40 & -0.24 & 0.53 & -2.73 & 0.45 \\
\hline & 10.0 & 0.06 & 0.18 & -0.04 & 0.27 & 0.07 & 0.06 & 0.47 & 0.06 & -0.05 & 0.11 & -0.74 & 0.11 \\
\hline 8 & 0.0 & 0.33 & & 0.33 & & 1.18 & & 7.77 & & 1.18 & & 7.77 & \\
\hline & 0.1 & 0.32 & 0.97 & -0.10 & 0.97 & 1.02 & 0.86 & 6.79 & 0.87 & -0.38 & 0.89 & -3.67 & 0.64 \\
\hline & 1.0 & 0.23 & 0.70 & -0.09 & 0.79 & 0.45 & 0.38 & 3.18 & 0.41 & -0.24 & 0.53 & -2.68 & 0.45 \\
\hline & 10.0 & 0.06 & 0.18 & -0.03 & 0.30 & 0.07 & 0.06 & 0.53 & 0.07 & -0.05 & 0.11 & -0.72 & 0.16 \\
\hline 9 & 0.0 & 0.32 & & 0.32 & & 1.17 & & 7.51 & & 1.17 & & 7.51 & \\
\hline & 0.1 & 0.31 & 0.97 & -0.11 & 0.97 & 1.01 & 0.86 & 6.55 & 0.87 & -0.40 & 0.88 & -3.85 & 0.64 \\
\hline & 1.0 & 0.23 & 0.72 & -0.09 & 0.81 & 0.45 & 0.38 & 3.18 & 0.42 & -0.24 & 0.54 & -2.81 & 0.45 \\
\hline & 10.0 & 0.06 & 0.19 & -0.04 & 0.28 & 0.07 & 0.06 & 0.51 & 0.07 & -0.05 & 0.11 & -0.76 & 0.11 \\
\hline 10 & 0.0 & 0.24 & & 0.24 & & 1.05 & & 5.64 & & 1.05 & & 5.64 & \\
\hline & 0.1 & 0.23 & 0.96 & -0.19 & 0.96 & 0.90 & 0.86 & 4.88 & 0.87 & -0.51 & 0.88 & -5.26 & 0.60 \\
\hline & 1.0 & 0.16 & 0.67 & -0.16 & 0.79 & 0.38 & 0.36 & 2.15 & 0.38 & -0.30 & 0.54 & -3.81 & 0.42 \\
\hline & 10.0 & 0.03 & 0.13 & -0.06 & 0.29 & 0.04 & 0.04 & 0.24 & 0.04 & -0.06 & 0.11 & -1.01 & 0.11 \\
\hline all & 0.0 & 1.48 & & 1.48 & & 7.21 & & 29.37 & & 7.21 & & 29.37 & \\
\hline & 0.1 & 1.42 & 0.96 & 1.01 & 0.97 & 6.28 & 0.87 & 27.05 & 0.92 & 5.00 & 0.89 & 14.11 & 0.77 \\
\hline & 1.0 & 1.02 & 0.69 & 0.85 & 0.81 & 3.00 & 0.42 & 16.18 & 0.55 & 3.16 & 0.56 & 11.10 & 0.59 \\
\hline & 10.0 & 0.25 & 0.17 & 0.32 & 0.30 & 0.54 & 0.07 & 3.56 & 0.12 & 0.68 & 0.12 & 3.54 & 0.18 \\
\hline
\end{tabular}

For more details see Table 3.

time constant. For example, a moving bar stimulus might have a velocity of about $5 \% \mathrm{sec}$. This bar may activate an S2 simple cell whose total receptive field width is about $1^{\circ}$. In this case, subficld antagonism (for example) should be sustained for about $200 \mathrm{msec}$. Because the time constant $\tau_{m}$ of pyramidal neurons is between 10 and $20 \mathrm{msec}$, we can consider the synaptic $g(t)$ to be essentially constant on this time scale. Finally, we are mainly concerned with the presence or absence of cortical inhibition, mediated by GABA. Evidence from work in rat hippocampus and pyriform cortex as well as rat and cat neocortex (Kehl and McLennan, 1985; Connors et al., 1988; Tseng and Haberly, 1988) suggests that the short-latency and fast IPSP seen upon stimulation of excitatory afferents to these areas is caused by activation of $\mathrm{GABA}_{\mathrm{A}}$ receptors, leading to a large increase in chloride conductance that reaches a peak at 18-25 msec (at $30-35^{\circ} \mathrm{C}$ ). The long latency and slow IPSP that follows the fast IPSP is caused by a smaller increase in potassium conductance-due to $\mathrm{GABA}_{\mathrm{B}}$ receptor activation-that lasts for many hundreds of milliseconds. Because even a fast conduc- tance increase with $t_{\text {peak }}=2 \mathrm{msec}$ leads to an increase in somatic conductance little different from that caused by a stationary synaptic input (compare Figs. $5 A$ and $6 B$ ), our results apply to the standard $\mathrm{G} \wedge \mathrm{B} \Lambda$-mediated inhibition seen throughout the cortex.

\section{Theoretical and numerical results}

On the basis of these assumptions, we derive theoretical expressions for the increase in somatic input conductance due to the activation of a single synapse in a dendritic tree of arbitrary geometry and investigate the nonlinear interaction among many, simultaneously active, synapses. We introduce 2 factors, the visibility $\Gamma$ in Eq. (15) and the attenuation $M$ in Eq. (26). $\Gamma$ is defined as the ratio of the change in somatic input conductance during synaptic input and the sum of the synaptic conductances and always obeys $0 \leq \Gamma \leq 1$ (for $g_{i}>0$ ). A large $\Gamma$ implies that most of the synaptic conductance input is actually visible from the soma. However, $\Gamma$ only represents a theoretical upper bound on the visibility, because additional considerations, such as noise, 
quality of the electrical recording setup, etc., place additional limitations on what can be detected from the soma (Rall, 1967).

Our theoretical results show that the observed conductance change at any location in the dendritic tree or cell body is always less than or equal to the actual synaptic conductance change (i.e., $0 \leq \Delta G_{s s} \leq g_{i}$ ) and that this conductance change does not depend on the synaptic reversal potential. For an infinite dendrite of constant diameter, the change in the "somatic" input resistance, $\Delta K_{\text {ss }}$, decreases exponentially, with a decay constant of one-half the length constant for small inductance inputs [Eq. (17)]. Thus, the visibility decays more rapidly in neurons that have relatively long and thin dendrites than those that have shorter and thicker dendrites. Because $\Gamma$ does not depend on the synaptic reversal potential, hyperpolarizing, shunting or excitatory conductance changes are all equally visible. Furthermore, changes in somatic input resistance (or input conductance) induced by synaptic input do not add linearly. The change in somatic input resistance in response to 2 (or more) synaptic inputs is always less than the change in input resistance expected by adding the individual changes in somatic input resistance caused by each synapse acting alone [Eq. (23)]. This is simply a reflection of the nonlinear interaction among conductance inputs.

Wc simulate the visibility problem in an idealized neuron consisting of 2 primary dendrites, each giving rise to multiple secondary branches. The performance of this model confirms our theoretical results and enables us to examine the effect of transient inputs. A transient synaptic conductance change is always less visible than a corresponding stationary change. However, the numerical simulations show that if the synaptic input changes approximately as fast as the membrane time constant $\tau_{m}$, then the measured change in input conductance is little different from the true change in input conductance (Fig. 7). Figure 8 illustrates the conductance change at the soma in response to 26 transient excitatory and inhibitory synapses, each with a peak conductance change between 2 and $5 \mathrm{nS}$. Due to the nonlinear interaction among synapses as well as temporal dispersion, only about $11 \mathrm{nS}$ are visible!

In our investigations of "real" cortical neurons, we use the most comprehensive quantitative data available to us. A number of workers have offered counts of presumed excitatory and inhibitory synapses in the visual cortex (Beaulieu and Colonnier, 1985; Peters, 1987). These data are not derived from extensive series of serial sections or from labeled inhibitory afferents, and so they cannot provide a clear picture of the spatial relationship between inhibitory synapses activated by the same afferent. For example, these data do not establish whether inhibitory terminations on spines are also associated with inhibitory terminations on the trunk dendrite and whether these inhibitory terminals arise from the same afferent. It is also not clear what the distribution of spinous and dendritic contacts is along the length of the dendritic shaft. For these data we must turn to serial electron microscopic reconstructions (White and Rock, 1980) or to combined light and electron microscopy of labeled inhibitory afferents (Martin et al., 1983; Somogyi et al., 1983; Kisvarday et al., 1985, 1987; Gabbott et al., 1988).

We here focus on the inhibitory action of GABAergic basket cells on their spiny target cells. Inhibitory basket cells include the large basket cells of layer 2 and 3 , the small basket or clutch cells commonly encountered in layer 4 , and the "deep" large basket cells of layer 5 and 6 (Somogyi et al., 1983; Kisvarday et al., 1985). We selected these cells not only because the nec- essary quantitative data were available, but because the basket cell is a relatively common type of inhibitory neuron in visual cortex and is likely to play a significant role in the control of cortical pyramidal cells (Somogyi and Martin, 1985). The other inhibitory cell types such as the axoaxonic or chandelier cell (Somogyi, 1977; Peters et al., 1982), as well as the duuble bouquet cell (Somogyi and Cowey, 1981), are less common and their mechanisms are less obvious. The GABAergic axoaxonic cell makes contact with the axon hillocks of pyramidal neurons, predominantly in the superficial layers. However, their synapses are rare by comparison with the inhibitory synapses of other cell types that are located elsewhere on soma and dendrites (Beaulieu and Collonier, 1985). The majority of double bouquet cell synapses make contact with dendritic shafts of other inhibitory cells (Somogyi and Cowey, 1981), and these do not concern us for the present. The remainder make contact with the spines and shafts of spiny cells, but there are no suitable data available that could enable us to simulate their possible actions. Given the predominance of basket cells among inhibitory interneurons and their significant innervation of the soma and proximal dendrites of spiny cells, any model of inhibitory mechanisms must take account of the basket cell system (Martin, 1988).

Our investigations of the basket-pyramidal interaction have shown that inhibition sufficient to yield significant attenuation of excitation ( $M<0.7$, for example) is accompanied by a large $(>30 \%)$ increase in somatic input conductance. This is consistent with the observations of Miles and Wong (1984), who found that single afferent IPSPs in hippocampal pyramidal cells were accompanied by a $7.5 \mathrm{nS}$ increase in input conductance. Because their average somatic input conductance in the absence of synaptic input was $33 \mathrm{nS}$, the inhibitory increase is about $23 \%$. In our simulations, more than $80-90 \%$ of the inhibitory conductance change due to typical basket cell inputs is visible from the soma (i.e., $\Gamma>0.8$ ), even for inhibitory conductances so large that the somatic input conductance increases by $200 \%$. This is the order of change in input conductance reported by Connors et al. (1988) for electrically evoked inhibition of cortical pyramids in cortical slices (see also Berman et al., 1989).

It has been argued that inhibitory inputs might occur exclusively on distal spines, and so their conductance changes could be hidden from the soma. However, there is no anatomical evidence for inhibitory afferents with such exclusivity. Somogyi et al. (1983) and Kisvarday et al. (1987) report that the basket cells (from which we drew our examples) made contact with both dendritic shafts and spines, and this configuration may well be typical of inhibitory control in the cortex. In our simulations we examined the effect of placing some inhibitory synapses on spines that also received excitatory input, but this modification did not appreciably affect the nature of our results. This is because the remaining inhibitory dendritic and somatic synapses dominate the changes seen in the soma. We did simulate the case where inhibition only contacted those spines also enervated by excitation, although such a specific anatomical arrangement has not been found. For our range of parameters, the resultant inhibitory conductance changes will be visible at the soma if they are to reduce the FPSP caused by excitation (Table 5). Detailed anatomical data of other inhibitory cell types are required to decide finally the important question of selective control of spines.

Our results lead us to the conclusion that the increase in somatic input conductance due to the activity of basket cells should be clearly visible from recording sites at or near the cell 
Table 5. The effectiveness and visibility of inhibition located only on dendritic spines on the layer 5 cell (Fig. 3A)

$$
R_{m}=10,000 \Omega \mathrm{cm}^{2}
$$

\begin{tabular}{|c|c|c|c|c|c|c|}
\hline$g_{C l}$ & $V_{s}$ & $K_{s s}$ & $G_{s s}$ & $\% \Delta G_{s s}$ & $\Gamma$ & $\mathrm{M}$ \\
\hline 0.0 & 0.73 & 23.27 & 42.97 & 0.0 & - & 1.00 \\
0.1 & 0.72 & 23.03 & 43.41 & 1.0 & 0.63 & 0.98 \\
1.0 & 0.62 & 21.38 & 46.77 & 8.8 & 0.54 & 0.84 \\
10.0 & 0.39 & 16.61 & 60.19 & 40.1 & 0.25 & 0.53 \\
\hline 0.0 & 0.73 & 23.27 & 42.97 & 0.0 & - & 1.00 \\
0.1 & 0.72 & 23.03 & 43.42 & 1.0 & 0.64 & 0.98 \\
1.0 & 0.61 & 21.22 & 47.12 & 9.7 & 0.59 & 0.83 \\
10.0 & 0.28 & 13.73 & 72.84 & 69.5 & 0.43 & 0.38 \\
\hline
\end{tabular}

$R_{m}=40,000 \Omega \mathrm{cm}^{2}$

\begin{tabular}{|c|c|c|c|c|c|c|}
\hline$g_{C l}$ & $V_{s}$ & $K_{s s}$ & $G_{s s}$ & $\% \Delta G_{s s}$ & $\Gamma$ & $\mathrm{M}$ \\
\hline 0.0 & 2.80 & 81.03 & 12.34 & 0.0 & - & 1.00 \\
0.1 & 2.64 & 77.55 & 12.90 & 4.5 & 0.79 & 0.94 \\
1.0 & 1.96 & 62.00 & 16.13 & 30.7 & 0.54 & 0.70 \\
10.0 & 1.30 & 45.82 & 21.83 & 76.9 & 0.14 & 0.47 \\
\hline 0.0 & 2.80 & 81.03 & 12.34 & 0.0 & - & 1.00 \\
0.1 & 2.63 & 77.42 & 12.92 & 4.7 & 0.82 & 0.94 \\
1.0 & 1.75 & 57.18 & 17.49 & 41.7 & 0.74 & 0.63 \\
10.0 & 0.44 & 21.48 & 46.55 & 277.2 & 0.49 & 0.16 \\
\hline
\end{tabular}

Inhibition either shares spines number 14-20 with excitation (upper part of each table) or is located on the dendrite just below the spines (lower part of each table). Excitation of amplitude $g_{c}=0.1 \mathrm{nS}$ and reversal potential $E=60 \mathrm{mV}$ are applied to all spines simultaneously. We use 2 different values of the specific membrane resistance $R_{m}$. For further details, see Table 2 .

body of cortical pyramidal cells. Technical and noise considcrations place a limit of $\Delta G_{s s} / G_{s s}^{*} \approx 0.2$ on the minimum change observable (Douglas et al., 1988). Our simulations show that in order to attenuate excitation significantly (i.e., $M<0.7$ ), the basket cell induces a relative somatic conductance increase of at least $30 \%$. This was true of both the Chloride and the Mixed models. Note that our Mixed model assumes that the basket cell input onto the pyramidal cell is associated with a $\mathrm{GABA}_{\mathrm{A}}$ postsynaptic receptor at the soma and a $\mathrm{GABA}_{\mathrm{B}}$ receptor in the dendritic tree.

Only one model provided appreciable inhibition associated with a relatively small increase in conductance. This was the model in which inhibition only acted by increasing a potassium conductance at the distal dendritic inhibitory synapses, independent of the proximal and somatic synapses typical of basket cells. The somatic EPSP was lowered in one case by about 9 $\mathrm{mV}$ with an $M$ factor of 0.94 , the most linear of all the cases that we tested. Thus, the reduction in the EPSP was largely duc to hyperpolarization, not to shunting. Hyperpolarizations of this kind were observed by Douglas et al. (1988). However, this model does not conform to the known synaptic innervation pattern of inhibitory basket cells.

\section{Functional implications}

The high visibility of inhibitory conductance changes in cortical neurons is due to the proximity of these synapses to the soma.
Given the thick apical dendrite (the diameter of the first 400 $\mu \mathrm{m}$ of the apical dendrite of the deep pyramidal cell of Fig. 3 is $4.4 \mu \mathrm{m}$ ), the electrotonic distance of even the most distant inhibitory basket cell synapse on our layer 5 pyramidal cell (see Fig. $3 A$ ) is 0.47 for $R_{m}=10,000 \Omega \mathrm{cm}^{2}$ and half of that value for the 4-times higher $R_{m}$ value (see Table 1). These conditions are not favorable for fractioning the dendritic field into local computational units. However, the anatomical structure of other cells, in particular those of retinal ganglion cells (Koch et al., 1982), is different from that of pyramidal cells. Ganglion cells have long and narrow dendrites, leading to a decreased length constant and to high distal dendritic input resistances that favor the action of silent inhibition. Thus, it is possible that direction selectivity in retinal ganglion cells is achieved by different mechanisms than in cortex (Amthor et al., 1984; Grzywacz and Amthor, 1989).

The failure to observe significant increases in somatic conductance during presentation of nonpreferred stimulation indicates that at least the basket cells do not exercise sustained inhibition during that response. This is consistent with the findings of Ferster (1986), who reported that inhibitory potentials have the same orientation selectivity as excitatory potentials. Our results, together with the experiments of Douglas et al. (1988), imply that synaptically mediated inhibition cannot play the dominant role in suppressing excitation for nonpreferred stimuli that has been assigned to it. For instance, the Barlow and Levick (1965) veto-scheme for direction selectivity depends simply on the phase relationship between excitatory and inhibitory conductance changes to determine preferred and null direction: both excitatory and inhibitory conductance changes have the same magnitude in both directions. While this model may be applicable to the retina, it appears that in cortex it is not. Massive inhibition is absent during nonpreferred stimulation, and massive excitation is present only during the preferred response.

One interesting model which could in principle explain the experimental findings relies on the tonic presence of both excitatory and inhibitory conductance changes (see, also, Martin, 1988). Stimulating the cell in its null direction or orientation is then postulated to decrease the conductance of the excitatory synapses from their steady-state level and to increase the conductance of the inhibitory synapses (and vice versa in the preferred direction). The cell would then effectively be inhibited while showing no net change in somatic input conductance [because the conductance increase associated with inhibition is canceled by the conductance decrease of excitation; see Eq. (21)]. Because such tonic input would most likely be mediated by feedback intracortical afferents, this "detailed balance" model is quite different from the type of feed-forward schemes proposed to underlie orientation or direction selectivity (for a review of these, see Ferster and Koch, 1987, and Martin, 1988). The type of models that need to be considered now must incorporate the massive inhibitory and excitatory feedback connections evident among all cortical cells.

\section{References}

Amthor FRC, Oyster CW, Takahashi ES (1984) Morphology of onoff direction-selective ganglion cells in the rabbit retina. Brain Kes 298:187-190.

Barlow HB, Levick WR (1965) The mechanism of directionally selective units in the rabbit's retina. J Physiol (Lond) 178:477-504.

Barrett EF, Barrett JN (1976) Separation of two voltage-sensitive po- 
tassium currents, and demonstration of a tetrodotoxin-resistant calcium current in frog motoneurons. J Physiol (Lond) 255:737-774.

Beaulieu C, Colonnier M (1985) A laminar analysis of round-asymmetrical and flat-symmetrical synapses on spines, dendritic trunks, and cell bodies in area 17 of the cat. J Comp Neurol 231:180-189.

Berman N, Douglas RJ, Martin KAC (1989) Inhibitory conductance changes are larger in vitro than in vivo. J Physiol (Lond) (in press).

Blomfield S (1974) Arithmetical operations performed by nerve cells. Brain Res 69:115-124.

Brown TH, Chang VC, Ganong AH, Keenan CL, Kelso SR (1988) Biophysical properties of dendrites and spines that may control the induction and expression of long-term synaptic potentiation. In: Longterm potentiation: from biophysics to behavior (Landfield $\mathrm{PW}$, Deadwyler SA, eds), pp 197-260. New York: Liss.

Carlen PL, Durand D (1981) Modelling the postsynaptic location and magnitude of tonic conductance changes resulting from neurotransmitters or drugs. Neuroscience 6:839-846.

Carnevale NT, Johnston D (1982) Electrophysiological characterization of remote chemical synapses. J Neurophysiol 47:606-621.

Connors BW, Malenka RC, Silva LR (1988) Two inhibitory postsynaptic potentials, and $G A B A_{A}$ and $G_{A B A}$ receptor mediated responses in neocortex of rat and cat. J Physiol (Lond) 406:443-468.

Crank J, Nicolson P (1947) A practical method for numerical evaluation of solutions of partial differential equations of the heat conduction type. Proc Camb Phil Soc 43:50-67.

Creutzfeldt OD, Kuhnt U, Benevento LA (1974) An intracellular analysis of visual cortical neurones to moving stimuli: responses in a cooperative neuronal network. Exp Brain Res 21:362-365.

Dean AF, Hess RF, Tolhurst DJ (1980) Divisive inhibition involved in directional selectivity. J Physiol (Lond) 308:84P.

Douglas RJ, Martin KAC (1989) Neocortex. In: The synaptic organization of the brain (Shepherd GM, ed) (in press).

Douglas RJ, Martin KAC, Whitteridge D (1988) Selective responses of visual cortical cells do not depend on shunting inhibition. Nature 332:642-644.

Douglas RJ, Martin KAC, Whitteridge D (1989) Intracellular responses of striate cortical cells to visual stimulation. J Physiol (Lond) (in press).

Durand D (1984) The somatic shunt cable model for neurons. Biophys $\mathrm{J}$ 46:645-653.

Dutar P, Nicoll RA (1988) A physiological role for $\mathrm{GABA}_{\mathrm{B}}$ in the central nervous system. Nature 332:156-158.

Ferster D (1981) A comparison of binocular depth mechanisms in areas 17 and 18 of the cat visual cortex. J Physiol (Lond) 311:623655.

Ferster D (1986) Orientation selectivity of synaptic potentials in neurons of cat primary visual cortex. J Neurosci 6:1284-1301.

Ferster D (1987) The origin of orientation selective EPSPs in simple cells of cat visual cortex. J Neurosci 7:1780-1791.

Ferster D, Koch C (1987) Neuronal connections underlying orientation selectivity in cat visual cortex. Trends Neurosci 10:487-492.

Fox SE, Chan CY (1985) Location of membrane conductance changes by analysis of the input impedance of neurons. II. Implementation. J Neurophysiol 54:1594-1606.

Gabbott PLA, Martin KAC, Whitteridge D (1988) Evidence for the connections between a clutch cell and a corticotectal neuron in area 17 of the cat visual cortex. Proc R Soc London [Biol] 233:385-391.

Grzywacz NM, Amthor FR (1989) A computationally robust model for retinal directional selectivity. In: Advances in neural information processing systems (Touretzky DS, ed), pp 477-484. San Mateo, CA: Morgan Kaufmann.

Heggelund P (1981a) Receptive field organization of simple cells in cat striate cortex. Exp Brain Res 42:89-98.

Heggelund P (1981b) Receptive field organization of complex cells in cat striate cortex. Exp Brain Res 42:99-107.

Jack JJB, Miller S, Porter R, Redman SJ (1971) The time course of minimal excitatory post-synaptic potentials evoked in spinal motoneurones hy group Ia afferent fibers. J Physiol (Lond) 21 5:353-380.

Jack JJB, Noble D, Tsien RW (1975) Electrical current flow in excitable cells. Oxford, UK: Clarendon P.

Kehl SJ, McLennan H (1985) An electrophysiological characterization of inhibitions and postsynaptic potentials in rat hippocampal CA3 neurons in vitro. Exp Brain Res 60:299-308.

Kisvarday ZF, Martin KAC, Whitteridge D, Somogyi P (1985) Synaptic connections of intracellularly filled clutch cells: a type of small basket cell in the visual cortex of the cat. J Comp Neurol 241:111137.

Kisvarday ZF, Martin KAC, Friedlander MJ, Somogyi P (1987) Evidence for intralaminar inhibitory circuits in striate cortex of cat. $J$ Comp Neurol 260:1-19.

Koch C, Poggio T (1985) A simple algorithm for solving the cable equation in dendritic lrees of arbitrary geometry. $J$ Neurosci Methods 12:303-315.

Koch C, Poggio T (1986) Computations in the vertebrate retina: motion discrimination, gain enhancement and differentiation. Trends Neurosci 9:204-211.

Koch C, Poggio T (1987) Biophysics of computation: neurons, synapses and membranes. In: Synaptic function (Edelman GM, Gall WE, Cowan WM, eds), pp 637-698. New York: Wiley.

Koch C, Poggio T, Torre V (1982) Retinal ganglion cells: a functional interpretation of dendritic morphology. Phil Trans R Soc London [Biol] 298:227-264.

Koch C, Poggio T, Torre V (1983) Nonlincar interactions in a dendritic tree: localization, timing, and role in information processing. Proc Natl Acad Sci USA 80:2799-2802.

Llinás RR (1988) The intrinsic electrophysiological properties of mammalian neurons: insights into central nervous system function. Science 242:1654-1664.

Marchiafava PL (1979) The responses of retinal ganglion cells to stationary and moving visual stimuli. Vision Res 19:1203-1211.

Martin KAC (1988) From single cells to simple circuits in the cerebral cortex. Q J Exp Physiol 73:637-702.

Martin KAC, Somogyi P, Whitteridge D (1985) Physiological and morphological properties of identified basket cells in the cat's visual cortex. Exp Brain Res 50:193-200.

Mascagni M (1989) Numerical methods for neuronal modeling. In: Methods in neuronal modeling: from synapses to networks (Koch C Segev I, eds), pp 439-484. Cambridge, MA: MIT.

Miles R, Wong RKS (1984) Unitary synaptic potentials in the guineapig hippocampus in vitro. J Physiol (Lond) 356:97-113.

Peters A (1987) Number of neurons and synapses in the primary visual cortex. In: Cerebral cortex, Vol 6: further aspects of cortical functions including hippocampus (Jones EG, Peters A, eds), pp 267-294. New York: Plenum.

Peters A, Proskauer C, Ribak CE (1982) Chandelier cells in rat visual cortex. J Comp Neurol 206:397-416.

Rall W (1964) Theoretical significance of dendritic tree for inputoutput relation. In: Neural theory and modeling (Reiss RF, ed), pp 73-97. Stanford, CA: Stanford UP.

Rall W (1967) Distinguishing theoretical synaptic potentials computed for different soma-dendritic distributions of synaptic inputs. J Neurophys 30:1138-1168.

Rall W (1974) Theoretical significance of dendritic tree for inputoutput relation. In: Neural theory and modeling (Reiss RF, ed), pp 73-97. Stanford, CA: Stanford UP.

Rall W (1989) Cable theory for dendritic neurons. In: Methods in neuronal modeling: from synapses to networks (Koch C, Segev I, eds), pp 9-62. Cambridge, MA: MIT.

Rall W, Burke RE, Smith TG, Nelson PG, Frank K (1967) Dendritic location of synapses and possible mechanism for the monosynaptic EPSP in motoneurons. J Neurophysiol 30:1169-1193.

Rose D (1977) On the arithmetical operation performed by inhibitory synapses onto the neuronal soma. Exp Brain Res 28:221-223.

Segev I, Parnas I (1983) Synaptic integration mechanisms: a theoretical and experimental investigation of temporal postsynaptic interactions between excitatory and inhibitory inputs. Biophys J 41:41-50.

Shepherd GM (1972) The neuron doctrine: a revision of functional concepts. Yale J Biol Med 45:584-599.

Sillito AM (1975) Inhibitory processes underlying the direction specificity of simple, complex, and hypercomplex cells in the cat's visual cortex. J Physiol (Lond) 271:699-720.

Sillito AM, Kemp JA, Milson JA, Beradi N (1980) A re-evaluation of the mechanism underlying simple cell orientation selectivity. Brain Res 194:517-520.

Smith TG, Wuerker RB, Frank K (1967) Membrane impedance changes during synaptic transmission in cat spinal motoneurons. J Neurophysiol 30:1072-1096.

Somogyi P (1977) A specific 'axo-axonal' interneuron in the visual cortex of the rat. Brain Res 136:345-350.

Somogyi P, Cowey A (1981) Combined Golgi and electron micro- 
scopic study of the synapses formed by double bouquet cells in the visual cortex of cat and monkey. J Comp Neurol 195:547-566.

Somogyi P, Martin KAC (1985) Cortical circuitry underlying inhibitory processes in cat area 17. In: Models of the visual cortex (Rose D, Dobson VG, eds), pp 514-523. New York: Wiley.

Somogyi P, Freund TP, Cowey A (1982) The axo-axonic interneuron in the cerebral cortex of the rat, cat and monkey. Neuroscience 7 2577-2607.

Somogyi P, Kisvarday ZF, Martin KAC, Whitteridge D (1983) Synaptic connections of morphologically identified and physiologically characterized large basket cells in the striate cortex of the cat. Neuroscience 10:261-294.

Stafstrom CE, Schwindt PC, Chubb MC, Crill WE (1982) Properties of persistent sodium conductance and calcium conductance of layer $V$ neurons from cat sensorimotor cortex in vitro. J Neurophysiol 53 : $153-170$.
Torre V, Poggio T (1978) A synaptic mechanism possibly underlying directional selectivity to motion. Proc R Soc London [Biol] 202:409_ 416.

Torre V, Poggio T (1981) A new approach to synaptic interaction. In: Theoretical approaches in neurobiology (Reichardt W, Poggio T, eds), pp 39-46. Cambridge, MA: MIT.

Tseng G-F, Haberly LB (1988) Characterization of synaptically mediated fast and slow inhibitory processes in piriform cortex in an in vitro slice preparation. J Neurophysiol 59:1352-1376.

White EL, Rock MP (1980) Three-dimensional aspects and synaptic relationships of a Golgi-impregnated spiny stellate cell reconstructed from thin serial sections. J Neurocytol 9:615-636.

Yamada W, Koch C, Adams P (1989) Multiple channels and calcium dynamics. In: Methods in neuronal modeling: from synapses to networks (Koch C, Segev I, eds), pp 97-134. Cambridge, MA: MIT. 